\title{
TÓPICOS Y ESTILOS EN EL EPÍLOGO DEL MENSAJE PRESIDENCIAL COSTARRICENSE
}

\author{
Carla Victoria Jara Murillo
}

\begin{abstract}
RESUMEN
En el presente artículo se analizan los epílogos de un corpus compuesto por 30 mensajes presidenciales costarricenses, a saber, el último de cada administración durante el período 19022008. El análisis se enfoca en los tópicos generales y en algunos rasgos particulares de estilo. El artículo forma parte de una serie de estudios realizados en el marco del proyecto de investigación "Análisis del Discurso Político en Costa Rica: Evolución y Perspectiva" (Instituto de Investigaciones Lingüísticas, 2004-2009) cuyos resultados previos son Jara Murillo 2006, 2008 y en prensa.

Palabras clave: análisis del discurso, discurso político, estilo, política costarricense.
\end{abstract}

\begin{abstract}
In this paper, the epilogues of a corpus of 30 presidential speeches are analyzed in relation to their topics and particular aspects of style. The speeches correspond to the last given to the Congress by each Administration during the period 1902-2008. This article is part of a series of papers (Jara Murillo 2006, 2008, in press) resulting from the research project "Análisis del Discurso Político en Costa Rica: Evolución y Perspectiva” (Instituto de Investigaciones Lingüísticas, 2004-2009).

Key words: discourse analysis, political discourse, style, Costa Rican politics.
\end{abstract}

\section{Introducción}

\subsection{Corpus y objetivo}

El presente artículo se deriva de la investigación "Análisis del Discurso Político en Costa Rica: Evolución y Perspectiva”, desarrollada en el Instituto de Investigaciones Lingüísticas de la Universidad de Costa Rica, durante los años 2004-2008.

Carla Victoria Jara Murillo. Profesora de la Escuela de Filología, Lingüística y Literatura, Universidad de Costa Rica. San Pedro, San José, Costa Rica.

Correo electrónico: carla.jara@ucr.ac.cr, cvjara@yahoo.com

Recepción: 31- 3- 2009

Aceptación: 29- 4- 2009 
El corpus de estudio está constituido por los Mensajes Presidenciales (en adelante MPs $)^{1}$ presentados ante la asamblea de los diputados ${ }^{2}$ el último $\mathbf{1}^{\circ}$ de mayo de cada administración (excepto por el del 16 de enero de 1949, sesión de instalación de la Asamblea Constituyente), por el período 1902-2008.

En el Anexo 1 se especifica, para cada MP, el emisor (ex presidente), su partido político, su período administrativo y la fecha de emisión del MP; así como la etiqueta de identificación, que consiste en el primer apellido del ex mandatario y el año de emisión del MP: Iglesias 02 identifica el primer texto del corpus, que corresponde al último mensaje presidencial de Rafael Iglesias Castro, emitido el $1^{\circ}$ de mayo de 1902.

En la etapa final del proyecto se tomó la decisión de incluir como último documento del corpus el mensaje presidencial de Óscar Arias Sánchez emitido el $1^{\circ}$ de mayo del año 2008, esto es, su segundo MP. Aunque no se ajuste a los criterios inicialmente establecidos para la selección del corpus (el último mensaje ante los diputados de cada administración), lo cierto es que otros cinco MPs del corpus tampoco se ajustan a ese criterio, por las razones históricas en las que se desarrollaron las respectivas administraciones. Estos cinco MPs son: González F 16 (se incluyó en el corpus su tercer y último mensaje); Tinoco 19 (segundo y último mensaje); Aguilar 20 (su único mensaje); Picado 47 (tercer y último mensaje), y Figueres F 49 (su mensaje ante la Asamblea Constituyente). A este conjunto de MPs atípicos, agregamos ahora Arias 08 (segundo mensaje; administración en proceso).

En la primera etapa del proyecto se analizó la estructura formal del MP y su contenido ("tópica") con particular referencia al cuerpo del discurso (Jara Murillo 2006); posteriormente se analizaron los tópicos y las funciones comunicativas de los exordios (Jara Murillo 2008) y se realizó una descripción comprensiva del acto comunicativo representado por el MP en el marco de la etnografía de la comunicación, con base en Hymes (1974, 1986), Saville-Troike (1989) y Corbaugh (2007) (Jara Murillo en prensa).

El presente artículo tiene como objetivo completar los trabajos previos con el análisis de los epílogos; en particular se comentarán los tópicos o temas recurrentes y algunos aspectos de estilo en el epílogo de cada MP, tanto en términos cualitativos como cuantitativos. Los epílogos se observarán en el marco de la periodización que se estableció en los trabajos arriba mencionados, con base en la estructura formal y tópica (en Jara Murillo 2006) y en los eventos histórico-políticos correspondientes (en Jara Murillo en prensa). De acuerdo con esos estudios, se segmentó el corpus en los siguientes cuatro períodos:

I Período: de 1902 (Iglesias Castro) a 1920 (Aguilar Barquero)

II Período: de 1924 (Acosta García) a 1949 (Figueres Ferrer)

III Período: de 1953 (Ulate Blanco) a 1982 (Carazo Odio)

IV Período: de 1986 (Monge Álvarez) a 2008 (Arias Sánchez)

\subsection{Estado de la cuestión}

Desde la perspectiva lingüística, no son muchas las investigaciones que se han publicado en Costa Rica enfocadas en el discurso político. Destacan principalmente los trabajos de Quesada Pacheco (1989, 1994, 1997, 2001), y sobre el discurso presidencial propiamente, Hernández Mata 1995². Los trabajos de Quesada Pacheco se concentran en el análisis de la persuasión en discursos electorales, lo cual dista mucho de mi objeto de estudio y de mi enfoque. Por otra parte, Pendones de Pedro (1991) hace un análisis lingüístico comparativo del 
discurso presidencial en el ámbito centroamericano: analiza tres discursos -de Óscar Arias Sánchez, Daniel Ortega Saavedra y José Azcona Hoyos respectivamente-, que se dieron en el marco de las negociaciones de Esquipulas ${ }^{4}$. Cabe destacar, sin embargo, que desde otras disciplinas sí encontramos gran diversidad de publicaciones referidas al discurso político y al discurso presidencial, las cuales pueden consultarse en la bibliografía ${ }^{5}$.

\section{Tópicos y estilos en el epílogo del MP}

\subsection{Aspectos preliminares}

En Jara Murillo 2006 se describe la forma y el contenido de los MPs a lo largo del período en estudio. La estructura formal se analizó en términos de tres subestructuras: título, marco (que consta de saludo y cierre) y discurso. La tópica, o conjunto de temas recurrentes (van Dijk 1999), se desarrolla en tres partes principales o secuencias: exordio, cuerpo y epílogo. En el mencionado artículo se describe y analiza la tópica del cuerpo y en Jara Murillo 2008 se describe la tópica del exordio y las funciones comunicativas que predominan en esta primera parte del MP.

El exordio típicamente está constituido por el primer segmento del discurso. El segmento consiste en una secuencia de párrafos que finaliza donde el emisor fijó (mediante un mayor espacio, asteriscos o un título) una marca formal de linde. El cuerpo se compone de todos los segmentos comprendidos entre la primera marca de segmentación posterior al saludo y la última marca de segmentación previa al cierre.

En la codificación de los textos, las tres secuencias discursivas fueron etiquetadas de la siguiente manera:

$\begin{array}{ll}\text { Exordio: } & \mathrm{S} 1=\text { segmento } 1 \\ \text { Cuerpo: } & \mathrm{S} 2 \ldots \mathrm{Sn} \\ \text { Epílogo: } & \mathrm{Sn}+1\end{array}$

Las secuencias exordio y epílogo por lo general presentan tópicos formulaicos (agradecimientos, felicitaciones, etc.) que cumplen básicamente las funciones conativa y emotiva. Según los términos de Jakobson, el modelo de la comunicación contiene los siguientes componentes y sus correspondientes funciones: hablante (función emotiva), oyente (función conativa), contexto (función referencial), mensaje (función poética), contacto (función fática), y código (función metalingüística).

Tal como señala Jakobson (1988: 33),

\footnotetext{
Cada uno de estos seis elementos determina una función diferente del lenguaje. Aunque distinguimos seis de sus aspectos básicos, apenas podríamos encontrar mensajes verbales que realizasen un cometido único. La diversidad no se encuentra en el monopolio de una de estas funciones varias, sino en un orden jerárquico diferente. La estructura verbal del mensaje depende, básicamente, de la función predominante. Pero, aun cuando una tendencia hacia el referente (...), una orientación hacia el CONTEXTO -en resumen, la función llamada referencial, "denotativa", "cognoscitiva"- es la tarea primordial de numerosos mensajes, la participación accesoria de las demás funciones de tales mensajes debe ser tenida en cuenta por el lingüista observador.
}

En otras palabras, si bien en toda instancia de comunicación el lenguaje cumple de alguna manera todas las funciones, en determinados tipos de comunicación unas son más prominentes que otras. Del esquema clásico general, nos interesan los siguientes componentes 
para describir las funciones comunicativas del epílogo, ya que el lenguaje político combina esencialmente y de manera estratégica estas tres funciones.

El hablante o emisor: Cuando el lenguaje se centra en este componente, cumple primordialmente la función "emotiva" o "expresiva"; esto es, "aspira a una expresión directa de la actitud de éste hacia lo que está diciendo. Esto tiende a producir la impresión de una cierta emoción, ya sea verdadera o fingida" (Jakobson: loc. cit.).

El oyente o receptor: "Orientada hacia el oyente, la función CONATIVA encuentra su más pura expresión gramatical en el vocativo y el imperativo" (Jakobson ibid:35).

El contexto: Cuando el lenguaje se refiere en especial a la realidad extralingüística que sirve de contexto a la comunicación, cumple básicamente la función referencial.

Como se ha mencionado, en Jara Murillo 2008 se establecen los tópicos del exordio en términos de sus funciones comunicativas. Se vio ahí que los tópicos son temas recurrentes a los que acuden los emisores en cada secuencia de su discurso. Por ello es necesario considerar un criterio de frecuencia. Por ejemplo, el tópico referencial "mandato constitucional y/o rendición de cuentas" (que alude al requerimiento del artículo 139 de la Constitución Política) es el más frecuente, ya que aparece en 20 de los 28 exordios considerados en ese trabajo ${ }^{6}$. De los tópicos que cumplen función referencial, que son la mayoría, el siguiente en frecuencia es el de la pasada campaña política y sus vicisitudes.

Los tópicos de función conativa (los que apelan al oyente) y emotiva (los que expresan sentimientos del hablante) son típicamente formulaicos y, en realidad, se mezclan en su función primordial de ganar la buena voluntad de la audiencia; esto se refleja claramente en su enunciación como "deber de cortesía", "deberes de amistad y gratitud", etc. Los que son más específicamente conativos, según su frecuencia de aparición son: saludo / bienvenida, felicitaciones, agradecimientos y deseos de éxito, siempre dirigidos al receptor inmediato, esto es, los diputados.

El tópico emotivo por excelencia es la satisfacción que manifiesta el emisor por la labor realizada, que aparece en diez de los 28 MPs del corpus. Con el fin de completar la caracterización de la tópica del MP, corresponde ahora señalar los temas que recurren en los epílogos.

\subsection{Análisis de los epílogos}

\subsubsection{Identificación del epílogo en el MP}

El epílogo fue caracterizado por Aristóteles (1953: 229) en la Retórica (III-19) de este modo: "en el epílogo hay que decir los puntos principales que han servido para la demostración. El principio será decir que ha hecho lo que había prometido, de manera que hay que decir de qué se trata y el por qué.” En el MP, sin embargo, esto no suele ser así; en él se presentan básicamente tópicos emotivos-conativos y tópicos referenciales de diverso carácter. En los epílogos más largos, por otra parte, se muestra una estructura argumentativa relevante para el MP en su conjunto, de tal modo que, desde el punto de vista cualitativo, una primera distinción entre los epílogos se da entre los puramente formulaicos y los que incluyen, además de los tópicos emotivos/conativos, una estructura argumental que remata estratégicamente la exposición hecha en el cuerpo del discurso.

El criterio para la identificación del inicio del epílogo, según la esquematización titulada del MP que se generaliza en el último período, es un subtítulo del tipo "Reflexiones Finales", o 
algo semejante. En los períodos anteriores, se da como marca de inicio del epílogo el último linde de segmento y la acotación de que ha terminado la parte expositiva del discurso ${ }^{7}$.

De acuerdo con la periodización propuesta y siguiendo un criterio análogo al utilizado en Jara Murillo 2008 para los exordios, un primer aspecto por observar será la longitud de los epílogos en términos de párrafos. En los siguientes apartados se presenta, para cada período, una tabla que incluye la cantidad total de palabras en cada MP, la cantidad total de párrafos, el promedio de palabras por párrafo, la cantidad de párrafos en el exordio, en el cuerpo, y finalmente, los aspectos cuantitativos que más interesan aquí: la cantidad de párrafos en el epílogo, la cantidad de palabras en el epílogo y el porcentaje de palabras dedicado al epílogo en cada MP.

Por el momento, vale la pena anticipar una aproximación general: en el primer período los epílogos constan típicamente de uno o dos párrafos. En el segundo período la preferencia es el epílogo de dos párrafos. En el tercero se distribuye la preferencia entre uno y seis párrafos; sin embargo, se da un caso extraordinario, el de Carazo 82, cuyo epílogo se desarrolla en 25 párrafos. En el cuarto período, el epílogo muestra una tendencia a extenderse: cinco de los siete MPs tienen epílogos de cinco a nueve párrafos, y se da también otro caso extraordinario, Calderón F 94, cuyo epílogo cuenta con 29 párrafos.

Para efectos de los análisis que se presentan en los siguientes apartados, tómense en cuenta las convenciones que se enlistan en la Tabla 1.

Tabla 1. Abreviaturas y convenciones utilizadas en el análisis de los epílogos

\begin{tabular}{|c|c|}
\hline $\mathrm{S}(\#)$ & segmento (número) \\
\hline $\mathrm{P}(\#)$ & párrafo (número) \\
\hline CONCL[ ] & $\begin{array}{l}\text { un enunciado conclusivo con función demarcativa (típicamente marca el linde entre el cuerpo } \\
\text { del MP y el epílogo; otras veces se utiliza para cerrar el epílogo) }\end{array}$ \\
\hline PRES [ ] & una aseveración (o varias en secuencia) en presente \\
\hline PAS [ ] & una aseveración en pasado (perfecto o imperfecto) \\
\hline ANT [ ] & una aseveración en tiempo antepresente (según la denominación de Andrés Bello) \\
\hline FUT [ ] & una aseveración en futuro \\
\hline POT/PAS [ ] & una aseveración de modalidad potencial ubicada en el pasado \\
\hline POT/FUT [ ] & una aseveración de modalidad potencial ubicada en el futuro \\
\hline DEONT [ ] & una aseveración de modalidad deóntica \\
\hline NOM[ ] & un enunciado nominal/unimembre \\
\hline EMOT[ ] & un enunciado con función emotiva \\
\hline CONAT [] & un enunciado con función conativa \\
\hline INT.RET[ ] & interrogación retórica \\
\hline // & nexo oracional \\
\hline ( ) & marcador explícito de aseveración sin efecto proposicional \\
\hline Otros & $\begin{array}{l}\text { deícticos subrayados, formas verbales en cursiva, si la aseveración es de polaridad negativa } \\
\text { su marcador se indica también en cursiva }\end{array}$ \\
\hline
\end{tabular}




\subsubsection{Primer período (1902-1920)}

Los aspectos cuantitativos del primer período se pueden apreciar en la Tabla 2, en donde, como en las siguientes tablas, los MPs aparecen en orden ascendente según el porcentaje de palabras que componen el epílogo en relación con el total de palabras del MP:

Tabla 2. Primer período: Relación cuantitativa del epílogo con el MP

\begin{tabular}{|c|c|c|c|c|c|c|c|c|}
\hline MP & $\begin{array}{c}\text { Total de } \\
\text { palabras }\end{array}$ & $\begin{array}{l}\text { Total de } \\
\text { párrafos }\end{array}$ & $\begin{array}{c}\text { Promedio } \\
\text { de palabras } \\
\text { por párrafo }\end{array}$ & $\begin{array}{c}\text { Párrafos } \\
\text { en el } \\
\text { exordio }\end{array}$ & $\begin{array}{c}\text { Párrafos } \\
\text { en el } \\
\text { cuerpo }\end{array}$ & $\begin{array}{c}\text { Párrafos } \\
\text { en el } \\
\text { epílogo }\end{array}$ & $\begin{array}{c}\text { Palabras } \\
\text { en el } \\
\text { ep. }\end{array}$ & $\begin{array}{c}\% \text { de } \\
\text { pals en } \\
\text { el ep. }\end{array}$ \\
\hline 04-Jiménez 14 & 1140 & 12 & 95 & 1 & 11 & 0 & 0 & 0.0 \\
\hline 03-González V 10 & 16464 & 290 & 57 & 6 & 283 & 1 & 36 & 0.2 \\
\hline 06-Tinoco 19 & 10226 & 116 & 88 & 2 & 113 & 1 & 72 & 0.7 \\
\hline 05-González F 16 & 23742 & 203 & 117 & 2 & 198 & 3 & 383 & 1.6 \\
\hline 02-Esquivel 06 & 6496 & 52 & 125 & 15 & 35 & 2 & 153 & 2.3 \\
\hline 01-Iglesias 02 & 3684 & 41 & 90 & 2 & 37 & 2 & 133 & 3.6 \\
\hline 07-Aguilar 20 & 3740 & 33 & 113 & 1 & 30 & 2 & 199 & 5.3 \\
\hline
\end{tabular}

En cuanto a tópicos, en el primer período predominan los de función emotiva-conativa; por lo general se trata de un voto para que los diputados entrantes acierten en sus decisiones. Epílogos típicamente emotivo-conativos de este período son los siguientes:

$\mathrm{S} 17$

P290 - CONAT/EMOT[Concluyo, señores Diputados, rogándoos dispenséis que por tanto tiempo haya abusado de vuestra atención, y recibáis, como muy sinceros, mis votos por el completo acierto de vuestras deliberaciones, para honra vuestra y beneficio de la patria.] (González V 10)

S10

P116 - EMOT/CONAT[Con la profunda convicción de que en todos y cada uno de los nuevos Representantes del Pueblo encontraré siempre el sano consejo y la patriótica colaboración necesarios para el éxito feliz de mis aspiraciones y labores de Gobernante, que no tienen otro norte que la honra y la felicidad de Costa Rica, hago los más sinceros y expresivos votos por el patriótico acierto de vuestras deliberaciones y tareas de legisladores.] (Tinoco 19)

S8

P40 - PRES [Si la labor administrativa durante el año de que os doy cuenta, último de mi Administración, no ha podido dar cima a importantes proyectos apenas iniciados, ni hacer efectivos de otra parte propósitos expuestos en mis anteriores Mensajes, débese ello a contratiempos y vicisitudes que con frecuencia se presentan en el curso regular de la Administración Pública, sin que basten a veces a contrarrestarlos ni la previsión ni el esfuerzo del Mandatario.]

P41 - EMOT/CONAT[Hago votos muy sinceros porque el elegido de los pueblos, que en breve habrá de sucederme en el ejercicio de la Primera Magistratura del Estado, lleve unos y otros, en cuanto ellos se conformen con las necesidades del momento y las justas aspiraciones del país, a término feliz; y, porque el acierto presida vuestras deliberaciones al secundarle en tan patriótica labor.] (Iglesias 02)

S20

P51- EMOT/CONAT[No pretendo, señores Diputados, que en virtud de la labor que dejo bosquejada, me haya hecho acreedor al aplauso público, por más que en toda ella resplandezcan mis anhelos de acertar, nunca colmados; ni estimo valedera esa labor para saldar en la más pequeña parte la deuda de gratitud que con la Nación contraje al ser elevado por su voluntad a la Alta Magistratura que ocupo; pero me atrevo a esperar que encontraréis en el conjunto de los esfuerzos que he desplegado por el bien del País, 
cualesquiera que hayan sido sus frutos, motivo para estimar que amé siempre el progreso y la felicidad de mis conciudadanos, y que a ellos he consagrado todo mi pensamiento y toda mi voluntad.]

P52 - EMOT/CONAT[Hago votos fervientes porque las tareas que hoy habéis iniciado, poniendo al servicio del País vuestra ilustración y vuestras conocidas virtudes cívicas, sean fecundas en bienes para esta comunidad que es nuestro hogar.] (Esquivel 06)

S7

P32 - PRES [La oposición de que en los últimos meses he sido blanco no me hace descender de este alto puesto con enconos ni decepciones, pues de antemano sabía que la función gubernativa trae consigo sinsabores y disgustos, cuando se hace abstracción de hombres y círculos, para cuidar del interés general.] PAS [Respeté esa oposición /y/ no la temí;] [a veces, ella fue consecuencia de pasiones sin freno, que en vez de enseñar, irritan;] [en otras, mesurada y razonadora, me sirvió para hacer rectificaciones en actos al parecer equivocados del Gobierno.]

P33 - EMOT [Al servicio de mi país he puesto toda mi buena voluntad, junto con el escaso caudal de mis conocimientos, una y otro, prodigados con cariño y constancia, sin que este afán haya disminuido un momento, ni aun en medio de las angustias y dolores más crueles que puede sufrir un hombre;] /y,/ EMOT/CONAT[al retirarme ahora tranquilamente a la vida privada, con la satisfacción íntima del deber cumplido, no puedo menos que pedir a Dios que os ilumine a vosotros en vuestras tareas y decisiones y que guíe también por el camino del acierto al distinguido y joven estadista que, con el beneplácito de todos, vendrá a regir los destinos del país. (Aguilar 20)

Los epílogos de este período que merecen comentario particular son Jiménez 14 y González F 16. El primero, por carecer de epílogo completamente, caso único en el corpus de estudio. El discurso concluye con una solicitud para que se otorguen ascensos a un grupo de militares que se enlistan en el discurso:

\section{S7}

P10 - El comportamiento de la fuerza pública, en sus dos organizaciones, se ha ajustado en un todo a la misión que le corresponde en un Gobierno de leyes. La obra de legalidad y preservación de las instituciones que desde el principio hasta el fin se impuso el Ejecutivo, ha descansado en la roca de la disciplina militar y en la devoción a sus deberes por parte de las guarniciones y la policía. Ese comportamiento de la fuerza pública la enaltece y la hace acreedora al reconocimiento nacional; y yo ruego, por creerlo de justicia, que otorguéis en favor de los militares de alta graduación, que estuvieron en servicio, los ascensos que no ha estado en manos del Ejecutivo poder conferir.

P11 - Esos militares son los siguientes: [LISTA]

P12 - El galardón no dudo merecerá un general aplauso y pondrá de relieve que la República premia, como es merecido, a los buenos y leales defensores del orden y las libertades políticas de los costarricenses. (Jiménez 14)

El epílogo de González F 16, por el contrario, es el más elaborado de este período. Siguiendo la organización temática de este discurso y a diferencia de todos los MPs siguientes hasta el cuarto período, el epílogo aparece titulado: Las dificultades pueden vencerse. Se propone así una tesis que será argumentada meticulosamente en los tres párrafos que componen el epílogo.

En los epílogos argumentativos, en oposición a los puramente formulaicos, la temporalidad constituye un eje estructurante del discurso y se manifiesta lingüísticamente mediante deícticos temporales (subrayados) y oraciones aseverativas cuyas formas verbales (en sus cláusulas principales) aparecen en antepresente ${ }^{8}$, presente y futuro (en cursiva). El epílogo de González F 16 constituye un excelente ejemplo para ilustrar esta articulación estratégica de los enunciados en términos de temporalidad.

S96 (TÍTULO:) Las dificultades pueden vencerse

P201 - CONCL[He tratado de exponeros con la mayor claridad posible mi criterio sobre la situación económica, fiscal y financiera del país y el rumbo que habremos de seguir en vista ella.] PRES [Sin pesimismo indebido veo y comprendo los males a que me refiero /y/ (me he convencido de que,) si 
muchos de ellos son graves y amenazadores, son también esencialmente superficiales y remediables;] /y/ PRES [(sin optimismo injustificado creo que) el país dispone de fuerzas vivas en su sano y robusto pueblo, así como de riquezas naturales, apenas comenzadas a explotar, para hacerles frente.]

P202- PRES [Si nuestra situación actual en muchos detalles es crítica, no por eso es falsa o malsana en el fondo.] ANT [La misma crisis comercial que se produjo a consecuencia de la guerra europea, al evidenciar nuestra enfermedad, nos ha ofrecido el remedio] /y/ [ha sido fértil en enseñanzas útiles.] PRES [Nuestro deber ahora es aprovechar esas enseñanzas y, con valor y confianza en el porvenir, encaminar la administración de nuestra querida patria por senderos nuevos y mejores, hacia un desarrollo cada día más sano y cada día más fecundo en bienes, tanto materiales como morales.] DEONT [Nuestro lema debe ser: En el bien social está el de cada uno de nosotros]

P203- PRES [Todas las medidas y todas las reformas que propongo se inspiran en esta convicción;] [todas ellas parten de un mismo criterio y tienden a un mismo fin;][todas ellas forman un conjunto orgánico] /y,/ [son como un programa de lo que, según firmemente creo, debe ser la obra de los que hoy formamos los Poderes Ejecutivo y Legislativo.] FUT [Quizá muchos de nosotros no trabajaremos ya por el bien del país en las nuevas y más fáciles condiciones que las reformas crearán para el Gobierno de la República;] [el período que la Constitución concede a nuestras gestiones terminará antes de que todo lo que os propongo que hagamos pueda dar tangibles resultados.] DEONT [Mas esta consideración no debe detenernos ante la tarea que se nos impone, ante los problemas que piden pronta solución:] PRES [no trabajamos para nosotros sino para que nuestros sucesores encuentren el camino expedito y abierto, para que lo reciban ellos todo preparado y para que nosotros y nuestros hijos podamos disfrutar de los beneficios de una labor gubernativa libre de todas las dificultades que hoy embargan la nuestra.] (González F 16)

\subsubsection{Segundo período (1924-1949)}

Tabla 3. Segundo período: Relación cuantitativa del epílogo con el MP

\begin{tabular}{|c|c|c|c|c|c|c|c|c|}
\hline MP & $\begin{array}{l}\text { Total de } \\
\text { palabras }\end{array}$ & $\begin{array}{l}\text { Total de } \\
\text { párrafos }\end{array}$ & $\begin{array}{c}\text { Promedio } \\
\text { de palabras } \\
\text { por párrafo }\end{array}$ & $\begin{array}{c}\text { Párrafos } \\
\text { en el } \\
\text { exordio }\end{array}$ & $\begin{array}{c}\text { Párrafos } \\
\text { en el } \\
\text { cuerpo }\end{array}$ & $\begin{array}{c}\text { Párrafos } \\
\text { en el } \\
\text { epílogo }\end{array}$ & $\begin{array}{c}\text { Palabras } \\
\text { en el ep. }\end{array}$ & $\begin{array}{c}\% \text { de pals } \\
\text { en el ep. }\end{array}$ \\
\hline 08 -Acosta 24 & 9028 & 94 & 96 & 5 & 84 & 5 & 122 & 1.3 \\
\hline 14-Picado 47 & 13591 & 108 & 126 & 1 & 104 & 3 & 234 & 1.7 \\
\hline 12-Cortés 40 & 9677 & 134 & 72 & 7 & 125 & 2 & 201 & 2.0 \\
\hline 09-Jiménez 28 & 5687 & 25 & 227 & 1 & 22 & 2 & 137 & 2.4 \\
\hline 10-González V 32 & 11398 & 111 & 103 & 3 & 106 & 2 & 320 & 2.8 \\
\hline 13-Calderón G 44 & 6665 & 58 & 115 & 2 & 54 & 2 & 197 & 3.0 \\
\hline 11-Jiménez 36 & 4819 & 39 & 124 & 0 & 37 & 2 & 166 & 3.4 \\
\hline 15-Figueres F49 & 4609 & 41 & 120 & 1 & 37 & 3 & 165 & 3.5 \\
\hline
\end{tabular}

Del segundo período, interesa destacar tres epílogos: Jiménez 28, González V 32 y Figueres 49. Jiménez 28 interesa como ejemplo de un epílogo casi carente de tópicos emotivos explícitos, que se manifiestan, sin embargo, mediante enunciados asertivos con un tono de optimismo y satisfacción. Además, la temporalidad intrínseca al MP se manifiesta claramente mediante el uso de las formas verbales principales de antepresente, presente y futuro:

$\mathrm{S} 19$

P24 - ANT [Durante todo el año han coexistido, sin salvedad de un sólo día y en toda su plenitud, el orden y las libertades.] NOM[Un año más de vida republicana, tranquila y efectiva; un año de trabajo, sin sobresaltos para nadie, de paz social.] PRES [Eso es todo;] /y/ [-echando una ojeada sobre el resto del mundo- eso es mucho.] ANT [La suerte ha sido tan bondadosa con la República, que no tiene el Ejecutivo que explicar ningún fracaso en daño del país, que prestar excusas por ningún desastre.] PRES [Si fracaso ha habido, es el de mis ansias por no haber podido servir mejor al país.]

P25 - FUT [Los señores Secretarios del Estado os rendirán cuenta detallada de los actos del Poder Ejecutivo, en sus respectivos departamentos; /y/ DEONT [si el Congreso deseare de mi parte más amplios informes, no tiene más que mandar.] (Jiménez 28) 
En contraste, el MP siguiente, González V 32, debido a las severas condiciones económicas que enfrentaba el país a causa de la Gran Depresión, muestra un tono de pesimismo que raya en lo trágico; en la emotividad que manifiesta el emisor se refleja, como en general ocurre a lo largo de todos sus MPs, el sentido de transparencia y sinceridad que caracterizaba a González Víquez:

\begin{abstract}
S12
P110 - CONCL[Concluyo, señores Diputados.] FUT [Dentro de una semana haré entrega del Mando a quien elijáis para Primer Designado.] EMOT[Me voy del puesto que me confió la voluntad popular, lleno de amargura. No tanto por los golpes crueles que me ha asestado la mala suerte, sino especialmente por no haber tenido habilidad bastante para conjurar los males de una crisis, que por ser universal, nos enrolló en sus redes, ni para remediar los males que con especialidad afectaban a nuestra tierra.] POT/ PAS [Pudieron preverse algunas consecuencias de esa crisis,] /pero/ PAS [en un principio no se perdió la esperanza de que fuera transitoria,] /y/ [la esperanza nos engañó.] [De pronto la crisis se presentó ya incontenible y arrolladora] /y/ [no había ya posibilidad de contrarrestarla.] [Sólo cabía entonces amenguar sus efectos.] [(El hecho descarnado es que) recibí el Poder en condiciones de holgura, /y/ PRES [(que) lo devuelvo en circunstancias de miseria. INT.RET[¿Fue mi culpa?] PAS [No fue mía toda,] /pero/ [alguna culpa tuve.] EMOT[A quien conozca mi temperamento y mis personales sentimientos, no sorprenderá la afirmación que hago de que me voy con el corazón lacerado; ni menos sorprenderá el deseo que formulo con toda mi alma, de que mi sucesor logre devolver al país su bienestar.] PRES [Costa Rica es un país pequeño pero pujante.] POT/FUT [La nueva Administración podrá, contando con mayor confianza y con mayores recursos, ordenar y mejorar su vida económica, y con ella su vida fiscal, -lo cual no me fue posible hacer por efecto de la lucha política que invadió con ira y en tono desusado todos los campos de la actividad nacional.]

P111 - EMOT/CONAT[Hago esta confesión y reconozco mis culpas, para hacer presente al país y a vosotros, sus dignos representantes, la necesidad imperiosa de que los ánimos se aquieten, de que el buen juicio impere por sobre todo y de que ante una situación delicada, nos unamos todos como buenos hijos de una sola madre gravemente herida por el destino.] (González V 32)
\end{abstract}

El epílogo de Figueres 49 muestra un paralelo interesante con el de González F 16 en la manera concisa y clara (cf. Jara Murillo en prensa, sección 3.3.6.4) en que la temporalidad se manifiesta como elemento estructurante del MP:

S11 Señores Constituyentes:

P39 - CONCL[Hemos narrado sucintamente la historia de los acontecimientos que condujeron a la fundación de la Segunda República. Hemos descrito las principales aspiraciones de esa nueva estructura nacional.] DEONT [Debemos ahora pediros que procedáis al desempeño de la sagrada misión que os ha sido encomendada con la altura que os caracteriza, y con vuestros corazones libres de las pequeñas pasiones políticas del momento.]

P40 - PRES [Para el cumplimiento de esa tarea ponemos en vuestras manos un instrumento que ha costado mucho conquistar: la libertad.] CONAT[Esperamos que sabréis usarlo.]

P41 - CONAT[En nombre de los mártires de toda la campaña os rogamos, nobles Padres de la Patria, que en todo momento tengáis presente solamente el interés general de ese pueblo que tanto espera de todos nosotros. Dios y la patria os observan. Si en vuestros pechos quedare algún resabio de humana pequeñez, desechadlo al llegar a este recinto.] DEONT [Aquí sólo grandeza debe haber.] ANT[La hora de inaugurar la Constituyente ha llegado.] CONAT[Los héroes caídos os dicen: La puerta está abierta, pasad!] (Figueres F 49)

A continuación se comentan brevemente los cinco epílogos restantes de este período. Acosta 24 contiene cinco párrafos cortos; el primero y el último establecen un marco emotivoconativo y los internos son argumentativos y se organizan en estructura paralela:

\title{
S12
}

P90 - EMOT[Antes de terminar, permitidme que envíe un abrazo de reconocimiento y de cariño a mis Secretarios y Subsecretarios de Estado, los de hoy y los de ayer, cuya dedicación a los negocios de la 
República, y cuya inteligencia y probidad, han sido los pilares de acero en que se asentó la Administración que va a fenecer.]

P91 - ANT [Los Poderes Públicos han funcionado libre y soberanamente.]

P92 - ANT [He procurado cumplir con exactitud todos mis deberes.]

P93 - ANT [Nunca he reclamado derechos de ninguna clase.]

P94 - CONAT/EMOT[Recibid, señores diputados, el homenaje de mi respeto y los votos que formulo porque en este recinto, aun en medio de las más furiosas tempestades, prevalezca solamente lo que haya de dar lustre, felicidad y paz a Costa Rica y a su Pueblo.] (Acosta 24)

Jiménez 36 presenta un epílogo sin tópicos explícitamente emotivos que sin embargo se manifiestan a través de una característica de su estilo: el uso de figuras retóricas, particularmente al inicio del primer párrafo:

S6

P33 - PRES [La marea ascendente de recuperación que se observa en todo el mundo, se hace sentir pues, hasta en nuestras playas.] [No hay razón para entonar ditirambos;] /pero/ [tampoco la hay para lamentaciones de Jeremías.] [Se siente como un renacimiento de primavera.] [Lo más malo del camino queda atrás.] [El país está tranquilo;] [los negocios, a ojos vistas van caminando,] [no aparece en el horizonte el amago de desdichas,] /y/ FUT [si hay en pie arduos problemas, como surgen en todos los tiempos, la cordura tradicional de los costarricenses continuará, con buen éxito, buscándoles solución.] [El paulatino progreso de Costa Rica seguirá su curso. PRES [Si se la compara en sus diversos aspectos con la de otros países, la situación de Costa Rica es una de las más llevaderas que soporta el linaje humano.]

P34 - CONCL[Este es, señores Diputados, a grandes rasgos, y tal como se presenta a mis ojos, el estado político de la República. Os rindo este informe en acatamiento del principio constitucional que así me lo ordena; (Jiménez 36)

\section{Los siguientes tres epílogos muestran ser típicamente emotivo-conativos:}

\section{$\mathrm{S} 21$}

P133 - EMOT/CONAT[Me sucede en la Jefatura del Estado un hombre cuyas meritorias cualidades coronadas por el más alto y bien entendido patriotismo, son prenda segura de acierto y de bienestar para la Nación. Si los señores Diputados han de cooperar como lo hicieron conmigo, en la obra administrativa que al Doctor Calderón Guardia corresponde desarrollar, podemos alentar fundada esperanza de que el éxito apetecido recompensará sus esfuerzos. Que esa armonía inalterable entre el Congreso y el Poder Ejecutivo durante los cuatro años de mi Gobierno, persevere con el que me sigue. Tales son mis anhelos; así debemos esperarlo y así la patria lo reclama.]

P134 - CONCL[Os he hecho, señores Diputados, un resumen de las obras llevadas a feliz término por la Administración Pública a mí confiada.] EMOT/CONAT[En ellas, así como en todas las otras actividades del Gobierno, he puesto honradez, trabajo sincero y patriótico, y apasionado empeño. Si se han derivado las ventajas deseadas y vosotros así lo reconocéis, me sentiré ampliamente satisfecho sin otro propósito que el de haber contribuido al bien de la República y con la sola aspiración de que la historia patria al remover el humus del pasado, permita que germine mi nombre para legítimo orgullo de mis hijos.] (Cortés 40)

\section{S11.2}

P57 - CONCL[Con este informe que aquí termina, concluye también mi Administración.] EMOT/ CONAT[Dentro de ocho días, el 8 de mayo en curso, que es la fecha que al efecto determina nuestra Carta Fundamental, haré entrega del Gobierno al Licenciado don Teodoro Picado, elegido por el pueblo para sucederme en el Poder, y cuyas relevantes prendas personales de orden moral e intelectual, constituyen la más segura garantía de acierto en las elevadas funciones que le corresponde desempeñar. Tengo la plena convicción de que su labor será muy fecunda en bienes para Costa Rica, sobre todo si, como lo espero y os lo ruego, continuáis prestándole, Señores Diputados, el apoyo y la importante colaboración con que a mí me habéis honrado durante los cuatro años de mi Gobierno, y que comprometió, en forma perdurable, mi más profunda y sincera gratitud.]

P58 - EMOT/CONAT[El errar es de humanos, y no tengo la pretensión de haber sido infalible; /pero/ quiero rogar por vuestro elevado conducto al pueblo costarricense, que abone a mis errores la buena fe y el propósito vehemente de servirlo del mejor modo posible, lema éste al que consagré en todo momento las mejores energías y los más puros anhelos de mi espíritu. (Calderón G 44) 
$\mathrm{S} 12$

P106 - ANT[Se ha mantenido inalterable el orden público.] [La campaña política que se inicia ha originado ya algunos incidentes entre elementos de los diversos partidos políticos y las autoridades,] /pero/ [no han sido hechos de gravedad.] EMOT[Confío sinceramente en el sentido de cordura y en la cultura de los costarricenses y espero que la campaña política venidera se desenvolverá en un ambiente de calma y tranquilidad y de respeto de los derechos de cada ciudadano. En lo que dependa del Poder Ejecutivo así será: en tres años de gobernar el país he dado suficientes pruebas de mi apego a la ley, de mi respeto por las libertades públicas y de mi inquebrantable propósito de garantizarlas por todos los medios a mi alcance.]

P107 - EMOT[Deseo dejar constancia del reconocimiento a que son acreedoras las modestas fuerzas armadas del país que en todo momento han dado reiterado testimonio de su disciplina y de su lealtad, y menciono también, con expresiones de gratitud y de simpatía la excelente labor que desempeña la Misión Militar Estadounidense, a cuyo frente se encuentra el Coronel Edwin J. Messinger, quien con su preparación y don de gentes ha sabido conquistarse la cariñosa estimación de los militares costarricenses.]

P108 - EMOT[Aprovecho esta oportunidad para formular votos muy fervientes por el éxito de las labores legislativas que hoy se inician y para presentar a los señores Diputados un cordial saludo, con protestas de mi estimación y aprecio.] (Picado 47)

\subsubsection{Tercer período (1953-1982)}

Tabla 4. Tercer período: Relación cuantitativa del epílogo con el MP

\begin{tabular}{lccc||ccccc}
\hline \multicolumn{1}{c}{ MP } & $\begin{array}{c}\text { Total de } \\
\text { palabras }\end{array}$ & $\begin{array}{c}\text { Total de } \\
\text { párrafos }\end{array}$ & $\begin{array}{c}\text { Promedio } \\
\text { de palabras } \\
\text { por párrafo }\end{array}$ & $\begin{array}{c}\text { Párrafos } \\
\text { en el } \\
\text { exordio }\end{array}$ & $\begin{array}{c}\text { Párrafos } \\
\text { en el } \\
\text { cuerpo }\end{array}$ & $\begin{array}{c}\text { Párrafos } \\
\text { en el } \\
\text { epílogo }\end{array}$ & $\begin{array}{c}\text { Palabras } \\
\text { en el ep. }\end{array}$ & $\begin{array}{c}\text { \% de pals } \\
\text { en el ep. }\end{array}$ \\
\hline 20-Trejos 70 & 43709 & 446 & 98 & 2 & 438 & 6 & 485 & 1.1 \\
19-Orlich 66 & 10427 & 104 & 100 & 5 & 97 & 2 & 144 & 1.4 \\
16-Ulate 53 & 15179 & 189 & 80 & 17 & 169 & 4 & 283 & 1.8 \\
17-Figueres F58 & 4451 & 100 & 45 & 11 & 85 & 4 & 121 & 2.7 \\
18-Echandi 62 & 11118 & 91 & 122 & 11 & 78 & 2 & 323 & 3.0 \\
22-Oduber 78 & 7135 & 84 & 85 & 1 & 79 & 4 & 238 & 3.1 \\
21-Figueres F 74 & 810 & 23 & 35 & 6 & 16 & 1 & 29 & 3.5 \\
23-Carazo 82 & 17888 & 184 & 97 & 8 & 151 & 25 & 1599 & 8.9 \\
\hline
\end{tabular}

Durante el tercer período, el epílogo tiende a distribuirse entre uno y seis párrafos; este último caso no necesariamente es el más largo, ya que la longitud de las oraciones depende del estilo sintáctico del emisor. Así por ejemplo Figueres F 58 presenta cuatro párrafos que suman seis oraciones (más tres nominales/unimembres) y 121 palabras, mientras que Echandi 62 tiene dos párrafos con un total de 323 palabras en 17 oraciones. Los siguientes son los epílogos en cuestión (entre paréntesis el número de oración):

S8 Señores Diputados:

P94 - (1) CONAT[ahora os corresponde a vosotros la lucha, en el aspecto legislativo.] (2) PRES[La Asamblea es el cuerpo más político del Estado.] (3) PRES[Es por eso el lugar donde hay mayor peligro, de que la Democracia se convierta en una pugna de pasiones, como fin en sí mismas, con olvido de la verdadera finalidad de la función gubernativa.]

P95 - (4) CONAT[Ojalá que vosotros descuidéis lo menos posible esa finalidad verdadera: el bien del pueblo. NOM[El bien material, el bien educacional, el bien espiritual.] NOM[La salud del hombre común, de su mujer, de sus hijos.] NOM[Su alegría, su moral, su dignidad.]]

P96 - (5) DEONT[Todo el mecanismo democrático, todos los programas, todos los empeños, deben ser medios para ese fin: el bien del pueblo.]

P97 - (6) EMOT/CONAT[iQue Dios os ilumine!] (Figueres F 58) 
S9

P72 - (1) CONAT[Y, finalmente, (creo que es mi deber) llamar la atención de esta Asamblea Legislativa sobre las diferencias que se presentaron entre mi Gobierno y la anterior Asamblea.] (2) EMOT[Lo hago sin acrimonia, sin resentimiento por la violencia injustificada con que algunos Diputados me trataron.] (3) PAS[Todo eso pasó definitivamente, como pasan siempre esas pequeñeces, /y/ (4) PRES[ahora me sitúo en un plano exclusivamente doctrinario, para que en lo futuro se evite la repetición de un conflicto que, si bien no llegó a nada grave, fue negativo para la obra de los dos poderes y dañino para los intereses de la República.] (5) PAS[Un grupo de aquella Asamblea, sin duda con entusiasmo juvenil, anunció al comienzo de mi Administración que gobernaría por su cuenta y riesgo, asumiendo una responsabilidad en la que no había meditado y, lo que es peor, ignorando o pretendiendo violar las funciones que corresponden a cada uno de los Poderes.] (6) PAS[La realidad fue muy distinta, felizmente, como no podía menos que serlo, /pero/ (7) (lo que conviene destacar es) el síntoma (que) se produjo en determinado momento, como efecto pasional del resultado de unas elecciones. (8) PRES[Como secuela documental de aquella situación, lo único que queda, posiblemente, es el número de vetos que el Poder Ejecutivo se vio obligado a oponer al Legislativo. (9) PRES[El balance es elocuente] /y/ (10) PRES[no requiere comentarios:] (11) PAS[de los ochenta vetos interpuestos, únicamente ocho fueron resellados.]

P73 - (12) PRES[Jefferson nos dice que no puede darse una tiranía más peligrosa que la de los Parlamentos,] /porque/ (13) PRES[es colectiva, todopoderosa e irresponsable,] /en tanto que/ (14) PRES[es elevada, sana e indispensable la función de dar leyes, que a ellos corresponde.] (15) EMOT[Abrigo, como todos los costarricenses, la firme esperanza y más aún, la seguridad de que aquella experiencia no volverá a repetirse.] (16) PRES[Hay confianza en esta nueva Asamblea, que hoy inicia sus labores, tanto en su integración como por la experiencia habida, /y/ (17) PRES[esto es un magnífico heraldo de mejores tiempos en el perfeccionamiento democrático de la República.] (Echandi 62)

Es interesante notar que en estos dos epílogos se acude al mismo tópico conativo: el llamado a la Asamblea Legislativa a cumplir sus funciones responsablemente. La recurrencia de este tópico muestra cómo en ese período las luchas interpartidistas en este órgano político eran acres. Esto era consecuencia lógica de la reciente lucha armada, la Revolución de 1948, a raíz de la cual emergieron los dos partidos que por la siguiente mitad del siglo se disputarían el poder político: Liberación Nacional y el grupo opositor a Liberación Nacional ${ }^{9}$.

Volviendo al texto del epílogo, en particular al primer párrafo de cada uno, obsérvese que mientras que Figueres F 58 enfoca el tópico desde una perspectiva general, descriptiva, utilizando todos los verbos en presente (corresponde, es, hay, se convierta), Echandi 62 introduce desde la primera oración los problemas que se presentaron en su gobierno de manera narrativa, en una perspectiva orientada hacia el pasado. Después de un enunciado de carácter emotivo que se despliega en la segunda oración y establece la temporalidad con el deíctico ahora y la frase en lo futuro, continúa con la narrativa de hechos pasados, en donde todos los verbos de primer plano aparecen en perfectivo (pasó, anunció, fue, se produjo, se vio obligado, fueron).

Los siguientes epílogos de este período son más formulaicos:

S15

P186 - PAS $[$ Hace tres años, en este mismo sitio y con el mismo motivo que hoy me trae, dije a los señores Diputados:]

P187 - CITA[“Agotaremos las fuerzas en la tarea que nos ha sido impuesta y responderemos a los imperativos de nuestra época. Trabajaremos más cada día, y más optimistas también cada día, fijo el pensamiento en que, con el concurso de todos, le esperan días de ventura a Costa Rica.”]

P188 - EMOT[Hoy, que me sirvo de la oportunidad para despedirme oficialmente de los legisladores, les digo que la fe que tuve en los destinos venturosos de la Patria durante los albores de la Administración, me alienta igualmente, fortalecida por la confianza en el contingente humano que es el mejor patrimonio y el más copioso caudal de la colectividad costarricense, cuando ya llega a su ocaso mi modesta vida pública.] p189 - EMOT[He tratado, a fuerza de procurar hacer lo mejor que puedo mi trabajo, y de dedicarle todo mi tiempo, de deshacerme de enemigos y ganar amigos. Si se reduce el número de los enemigos, aumenta el de los amigos y esa es una de las tareas del que quiera gobernar con la opinión, sin la cual, no hay gobierno con virtud ni fortaleza. Si el número de los amigos se mantiene, pero aumenta paralelamente el 
de los enemigos, la fortuna política es incierta. Me animan el deseo y la esperanza de no haber disminuido en mucho el número de mis amigos, ni haber acrecentado el de mis adversarios. Solo así se pueden y se deben articular esfuerzos por tratar de hacer un gobierno que aspire a que, como en el pensamiento chino, pueda dejar el sable mohoso, el arado resplandeciente, vacía la cárcel y el granero lleno.] (Ulate 53)

S40

P103 - CONCL[Esta es, en sus grandes líneas, la tarea cumplida. Esta la labor en servicio de mi pueblo.]

P104 - EMOT[Para todos los funcionarios de la Administración Pública; para todos los costarricenses que me dieron su colaboración; para aquellos que, con su vigilancia ciudadana y sus críticas, me forzaron a examinar mejor la labor que estaba realizando, para convencerme de sus bondades o para rectificarme sus defectos; a los Organismos Internacionales, que nos extendieron su colaboración en forma de aporte financiero, de consejo técnico, de ejemplo constructivo o de aplauso generoso; para todos ellos la gratitud profunda de este costarricense que, constituido en el Primer Mandatario de la Nación, solo aspiró a ser el modesto Primer Servidor de su pueblo para realizar, con el concurso de tantos y con la ayuda de Dios, lo que es una convicción y un ideal en su vida: mandar es servir.] (Orlich 66)

\section{S5 PALABRAS FINALES}

S5.1 Señores Diputados:

P441 - CONCL[He tratado de abarcar en este Mensaje los diversos aspectos que debe contener conforme al texto constitucional respectivo, y aunque haya resultado largo son muchas las actividades realizadas que no he podido mencionar. Las Memorias que deben presentaros los Ministros de Gobierno así como las de las instituciones autónomas del Estado habrán de proveeros de mucha de la información adicional que os pueda ser de utilidad para tener una vista más completa sobre el estado de la Nación.]

P442 - EMOT[Es, por supuesto, mucho más lo que habríamos deseado poder realizar en favor del progreso y bienestar de cada hogar costarricense. Pero me sentiría muy satisfecho si el presente Mensaje os dejara, en suma, la idea de que no faltó esfuerzo alguno de nuestra parte para cumplir bien nuestros deberes como integrantes del Poder Ejecutivo y de que, por sobre todo, fuimos respetuosos de la juridicidad, del Derecho y asimismo de los derechos y de los criterios ajenos.]

P443 - CONAT/EMOT[Os ruego que, antes de concluir, me permitáis expresar honda satisfacción por la manera feliz en que se han mantenido las relaciones entre la Iglesia y el Estado, dentro de un ambiente de cordialidad y respeto mutuo pero sin intervención alguna en las esferas de acción propia de una y del otro.] P444 - CONAT/EMOT[Asimismo os ruego me permitáis manifestar en nombre del Gobierno y en representación de la Nación, la profunda estima que tenemos por cada uno de los distinguidos integrantes de las representaciones diplomáticas acreditadas en el país, pues todos nos han dado muestras claras del afecto que sienten por Costa Rica, tanto personalmente ellos, como los ilustrados Gobiernos que representan.]

P445 - EMOT[Habría deseado expresar nuestra honda gratitud individualmente a cada uno de los países que, de una manera u otra, regularmente y de muy diversas formas o en los momentos en que nuestra Patria sufría una calamidad, nos han brindado generosamente su ayuda. Pero me encontré con que tenía que citar a treinta países y a la Santa Sede, es decir, prácticamente a todas las naciones que nos honran al tener en San José la sede de sus representaciones diplomáticas. Esa expresión de gratitud y reciprocidad en el afecto, de parte de los costarricenses, es honda, muy sentida y va dirigida a todos los Excelentísimos Jefes de las Misiones Diplomáticas aquí presentes, a sus ilustrados Gobiernos y a los pueblos de todas esas naciones amigas.]

S5.2 [Vocat] Señores Diputados:

P446 - EMOT/CONAT[Tengo conciencia clara de la responsabilidad y de la trascendencia de los deberes que asumís como representantes del pueblo costarricense, en esta época de la historia en que los cambios se suceden en el mundo cada día con mayor velocidad. Por ello deseo, desde lo más hondo de mi ser, que Dios ilumine vuestras mentes y os depare el don de percibir el bien común cada vez que tengáis que tomar una decisión en vuestra calidad de representantes del pueblo. Todo para el mayor bien de Costa Rica.] (Trejos 70)

S6 Señores diputados:

P23 EMOT[Me voy del gobierno tranquilo, confiando el futuro de la Patria a Dios, a nuestros gobernantes venideros, y a la benevolencia y la sabiduría de nuestro pueblo.] (Figueres F 74)

\section{S12 SEÑORES DIPUTADOS:}

P81 - EMOT[Termino mi período de Gobierno en paz con mi conciencia, dejando una Costa Rica mejor de lo que era. Muchas veces he preguntado al ciudadano si vive hoy mejor que hace cuatro años, y su 


\begin{abstract}
respuesta es afirmativa. Pero lo más importante es que le he preguntado si él cree que vivirá mejor dentro de cinco años, y también me ha dicho que sí. Es decir, dejo un Gobierno que ha logrado engendrar el optimismo en el costarricense. Con ese optimismo, con esa fe, Costa Rica, tiene su futuro asegurado.] P82 - EMOT[En los campos crecen los siembros. Los graneros están llenos y los rifles enmohecidos. Los niños sonríen. El temple del Pueblo es acerado; su vocación más democrática; sus propósitos más humanos. La Nación marcha así, serena y confiadamente, hacia su mayor grandeza. A nada más puede aspirar un Gobernante.]

P83 - EMOT[Me vuelvo al hogar feliz de haber servido con devoción a Costa Rica. Dios me ayudó a tener paciencia y a perdonar a quienes me ofendieron, y también humildad para solicitar perdón a quienes pude haber ofendido. Cada costarricense me ayudó, con su calidad humana excepcional, a mantener y fortalecer cada una de las cualidades que heredamos de nuestros antepasados.]

P84 - EMOT[Siete Jefes de Estado y veintiocho Presidentes hemos sido los directores de este bello país, favorito del Creador. Pasar a la historia en su compañía es el don más preciado de mi vida. Por ello: ¡GRACIAS COMPATRIOTAS!] (Oduber 78)
\end{abstract}

El epílogo que más llama la atención en este período, por su longitud anormal, es Carazo 82, último MP del período. Este epílogo refleja, como señala Halliday (cf. Halliday y Hasan 1989), cómo el texto lleva siempre marcas del contexto, no solo en su contenido proposicional, donde obviamente encontraremos los hechos extralingüísticos a que se hace referencia, sino en otros aspectos que son parte integral del texto; en este caso su longitud. Esto es, algo extraordinario sucedía para que esta secuencia del MP, el epílogo, que normalmente se compone de unos pocos párrafos en los que se despliegan unos tópicos por lo general formulaicos, aparezca de repente compuesto por 25 párrafos con un total de 1.599 palabras ${ }^{10}$. Por obvias razones de espacio no puede ser reproducido aquí en su totalidad.

En cuanto a la estructura temática y argumental de este desproporcionado epílogo, se verá que también es anormal. Su segmentación se justifica por el subtítulo "Consideraciones Finales", así como por la temporalidad que establece el primer enunciado (con el deíctico ahora), que también sirve como marca de linde entre el cuerpo y el epílogo:

\title{
S14 CONSIDERACIONES FINALES \\ S14.1 \\ P160 - Permitidme ahora, señores diputados, algunas consideraciones que juzgo importantes sobre el futuro de Costa Rica. Durante estos años hemos vivido sin ayuda financiera internacional y me atrevo a vaticinar que vamos saliendo adelante sin ella. Si creemos que la ayuda externa tradicional nos viene a solucionar todos los males, nos habremos equivocado. (Carazo 82)
}

Hasta entonces, solo el epílogo de Trejos 70 (y el de González F 16, aunque con muy distinta estrategia, como se vio) aparece subtitulado, mediante el nominal "Palabras Finales". Hasta aquí vemos una estrategia muy parecida; sin embargo, mientras que el epílogo de Trejos 70 está constituido por un solo segmento de seis párrafos (dividido en dos subsegmentos mediante el vocativo "señores diputados"), Carazo 82 presenta una estructura temática extrañamente jerarquizada, con dos segmentos después del marcado mediante "CONSIDERACIONES FINALES", y otras tantas subsegmentaciones con o sin título (se respetan las mayúsculas y minúsculas del documento original):

S14 CONSIDERACIONES FINALES

S14.1 (P160)

S14.2 Respeto y dignidad (P161-162)

S14.3 Justicia social internacional y el plan del Presidente Reagan para Centro América y el Caribe (P163-168)

S15 PAZ CON LIBERTAD (P169-174)

S16 APOYO IRRESTRICTO AL PROXIMO GOBIERNO [Vocat] Señores diputados:

S16.1 (P175-179)

S16.2 Unidad en lo esencial o pacto social (P180-184) 


\subsubsection{Cuarto período (1986-2008)}

Tabla 5. Cuarto período: Relación cuantitativa del epílogo con el MP

\begin{tabular}{|c|c|c|c|c|c|c|c|c|}
\hline MP & $\begin{array}{c}\text { Total de } \\
\text { palabras }\end{array}$ & $\begin{array}{l}\text { Total de } \\
\text { párrafos }\end{array}$ & $\begin{array}{c}\text { Promedio } \\
\text { de palabras } \\
\text { por párrafo }\end{array}$ & $\begin{array}{c}\text { Párrafos } \\
\text { en el } \\
\text { exordio }\end{array}$ & $\begin{array}{c}\text { Párrafos } \\
\text { en el } \\
\text { cuerpo }\end{array}$ & $\begin{array}{c}\text { Párrafos } \\
\text { en el } \\
\text { epílogo }\end{array}$ & $\begin{array}{c}\text { Palabras } \\
\text { en el ep. }\end{array}$ & $\begin{array}{c}\text { \% de pals } \\
\text { en el ep. }\end{array}$ \\
\hline 29-Pacheco 06 & 5408 & 170 & 32 & 9 & 152 & 9 & 186 & 3.5 \\
\hline 30-Arias 08 & 3763 & 40 & 94 & 6 & 32 & 2 & 180 & 4.8 \\
\hline 28-Rodríguez 02 & 11664 & 115 & 101 & 11 & 96 & 8 & 582 & 5.0 \\
\hline 27-Figueres O 98 & 8982 & 78 & 115 & 2 & 71 & 5 & 626 & 7.0 \\
\hline 24-Monge 86 & 7976 & 87 & 92 & 2 & 78 & 7 & 669 & 8.4 \\
\hline 25-Arias 90 & 6455 & 71 & 91 & 12 & 50 & 9 & 794 & 12.3 \\
\hline 26-Calderón F 94 & 9723 & 233 & 42 & 4 & 200 & 29 & 1197 & 12.3 \\
\hline
\end{tabular}

Finalmente, en el cuarto período, mientras que la extensión general del MP tiende a reducirse, el epílogo tiende a extenderse, con un promedio de alrededor de siete párrafos, excluyendo el caso anormal de Calderón F 94, con 29 párrafos.

A continuación se presenta una breve descripción de los siete epílogos del último período. Los tópicos siguen siendo emotivos y conativos; sin embargo -y la propia longitud de cada uno nos da elementos para considerarlo así-, estos epílogos son mucho más elaborados y complejos desde el punto de vista retórico y argumentativo. En el Anexo 2 se transcriben en su totalidad para invitar a otros investigadores a que los analicen con detalle, ya que por su extensión no sería posible analizarlos aquí como se hizo con los de los tres períodos anteriores. En lo que sigue extraeré la estructura temática de cada epílogo atendiendo al concepto de "perspectiva" de Grimes (1975), según el cual cada segmento de discurso tiene un punto de partida que constituye su tema. En el caso de la oración, el tema es el constituyente inicial. En términos de párrafos (un nivel más alto de organización textual), la primera oración de cada párrafo constituye su tema ${ }^{11}$.

El epílogo de Monge 86 se titula "Diálogo y consenso nacional" y consta de 7 párrafos divididos en cuatro subsegmentos delimitados por el vocativo "Señores diputados". La estructura temática es la siguiente:

S32.1 [Vocat:] Señores diputados:

P80 Saber escuchar es, a mi juicio, una de las principales obligaciones de un Jefe de Estado.

P81 No se llega a la Presidencia de la República a imponer verticalmente las propias ideas.

P82 Por ello, desde el 8 de mayo de 1982, impuse la norma del diálogo y el consenso como fundamento de la acción de mi Gobierno.

P83 He escuchado a los sectores organizados y también, por encima de unos y otros, poderosos o no poderosos, he estado permanentemente atento a la voz del pueblo /y/ ...

S32.2 [Vocat:] Señores diputados:

P84 Ustedes encontrarán los detalles de esta rendición de cuentas en los informes parciales que, conforme a la Constitución Política, los Señores Ministros y Presidentes Ejecutivos entregarán a la Asamblea Legislativa.

S32.3 [Vocat:] Señores diputados:

P85 Este es mi último mensaje a la Asamblea Legislativa.

S32.4 [Vocat:] Señores diputados:

P86 Juntos hemos salvado la Paz.

P87 Juntos -y solo juntos- podremos cumplir el compromiso histórico, de heredar a las futuras generaciones una Costa Rica en paz y libertad -sí, en paz y libertad- pero también heredar una Costa Rica más justa, más equitativa, más solidaria y con menos pobreza... Muchas Gracias. (Monge 86) 
El epílogo de Arias 90 consta de 9 párrafos de mediana longitud; no presenta subsegmentaciones y su inicio se marca con el vocativo "Amigas y amigos míos", siendo este el único MP del corpus que echa mano a esta estrategia de cortesía positiva (Brown y Levinson 1987). Es de observar que este cuidadoso epílogo cumple con la descripción propuesta por Aristóteles (ver 2.2.1 supra). A continuación se muestra la estructura temática:

\footnotetext{
P63 En pocos días entregaré el Gobierno.

P64 Siempre sostuve que Costa Rica podría vencer cualquier obstáculo cuando las causas que emprendía eran aquellas en las que lograba un amplio consenso, por encima de divisiones políticas.

P65 Para el robustecimiento de nuestra democracia, para asegurarnos el respeto mutuo entre gobernantes y gobernados, nada es más sagrado que velar por la honestidad de los servidores públicos.

P66 También por consenso aprobamos la Ley de Psicotrópicos, que es una de las más avanzadas del mundo para combatir el narcotráfico.

P67 Nos complace haber convertido en realidad, la Sala IV de la Corte Suprema de Justicia con jurisdicción constitucional.

P68 Quiero señalar también que como la Constitución requiere mayoría calificada para empréstitos externos, hubo ocasiones en que estas mayorías se postergaron largamente en el tiempo por razones políticas o simplemente no se lograron por las mismas razones.

P69 Quiero dar las gracias a quienes me acompañaron en mi gestión de gobierno, desde el ministro de cada cartera hasta el más humilde servidor público.

P70 Las últimas páginas de este siglo nos presentarán retos como pocas veces en la historia.

P71 Recibí el Gobierno hace cuatro años de don Luis Alberto Monge. (Arias 90)
}

El epílogo de Calderón F 94, como en el caso de Carazo 82, es anormal en su longitud, ya que consta de 29 párrafos y 1.197 palabras. Sin embargo, este epílogo se caracteriza por contener párrafos muy breves, la mayoría de una única oración, y por la estructura paralela que se establece entre varios de ellos. Se divide en dos subsegmentos cuyo linde está constituido por el vocativo "honorables diputados". Se titula "Reflexiones finales" y muestra la siguiente estructura temática:

S6.1

P205 He mencionado algunas de nuestras victorias durante estos 4 años.

P206 Costa Rica está en el camino correcto.

P207 Hoy entregamos un país con una economía estable y en pleno proceso de expansión.

P208 Hoy entregamos una economía que crea empleos, mejores salarios y una más alta calidad de vida.

P209 Hoy entregamos una economía en pleno proceso de modernización y de inserción en la economía mundial.

P210 Hoy entregamos un país con menos inflación, con una de las inflaciones más bajas de la América Latina.

P211 Hoy entregamos un país con menos pobreza, un país con los índices más bajos de pobreza de nuestra historia.

P212 Hoy entregamos un país con 96.000,00 nuevas viviendas.

P213 Pero, sobretodo, hoy entregamos un país con más confianza en sí mismo y con más optimismo en el futuro.

P214 Si continuamos en el camino correcto de la modernización económica, de la austeridad fiscal, de la ética en la función pública, del control de la inflación y de la participación de Costa Rica en la economía mundial, tendremos garantizado un futuro de estabilidad, de crecimiento sostenido y de avance hacia el desarrollo.

P215 La reforma económica debe continuar.

S6.2 [Vocat:] Honorables Diputados:

P216 Hace cuatro años nos comprometimos ante los padres de nuestra nacionalidad a dirigir un gobierno de consenso nacional, fiel a los principios de nuestra idiosincrasia.

P217 Algunos pocos se fijan en nuestros errores.

P218 Hace unas semanas dos mujeres costarricenses me escribieron una carta de balance sobre nuestro gobierno.

P219 "Yo miro hacia el pasado y no me asusta, yo miro hacia el futuro y no lo temo, yo miro hacia la altura y la vislumbro, yo miro a la bajura y la comprendo, yo miro en el presente la confluencia de todos los caminos de lo eterno". 
P220 Gracias a estas costarricenses por sus palabras y por su aliento.

P221 Salgo, con unos años más, pero salgo enriquecido por la experiencia de dirigir esta República, escuchando las voces y los consejos, no solo de funcionarios y de colaboradores, sino las voces, los consejos del pueblo.

P222 Ser Presidente de Costa Rica es ser leal a sus valores.

P223 Ser Presidente de Costa Rica es ser un oyente de las aspiraciones y de las necesidades del pueblo. P224 Al final de la jornada, en mi corazón solo siento gratitud y agradecimiento hacia ese pueblo y hacia todos los colaboradores que me ayudaron a escuchar la voz de ese pueblo.

P225 Al final de la jornada, en mi corazón solo siento gratitud y agradecimiento, incluso a quienes me vieron como adversario y a quienes yo solo vi como hermanos costarricenses con opinión diferente.

P226 Hay muchos a quienes quiero agradecer.

P227 Ella es una persona a quien conozco desde hace 40 años y quien me ha impresionado con su talento y con su valor.

P228 De ella me ha impresionado su compasión.

P229 En Gloria me ha impresionado su visión de optimismo y de futuro.

P230 Con la ayuda y con la inspiración de Dios, hemos logrado mucho estos últimos años.

P231 Yo estoy orgulloso de esta nación, orgulloso de ser costarricense, orgulloso de decirle a mi sucesor: esta es mi querida Costa Rica.

P232 Tomemos con cuidado a esta nuestra Costa Rica.

P233 ¿Que Dios bendiga a esta República! Muchas gracias. (Calderón 94)

Figueres O 94 presenta un epílogo de 5 párrafos extensos. Constituye la última parte de un discurso estructurado en tres grandes segmentos y se titula "Mi profundo agradecimiento al pueblo costarricense". Los párrafos se caracterizan por contener, además de los tópicos formulaicos, mayor contenido proposicional. La estructura temática es la siguiente:

P74 Mi exposición llega a su fin y no quiero terminarla sin expresar a cada uno de ustedes la inmensa satisfacción y el profundo orgullo que siento por haber podido servirles como su Presidente.

P75 Durante estos años tan intensos, visité cada rincón del país y estuve en muchas empresas, en muchas comunidades y en muchas instituciones públicas.

P76 En todo lo que vi y lo que sentí, encontré siempre reflejado el espíritu sabio y generoso de nuestro pueblo.

P77 En los actos y decisiones innumerables de todos los costarricenses, es donde se ha resuelto la disyuntiva entre ser un país más solidario o ser un país más lleno de egoísmos, entre ser un país más próspero e innovador o ser un país más retrasado y estancado, entre ser un país que se reconcilia con la naturaleza o uno que la trata con violencia y con descuido.

P78 Con ese espíritu generoso y emprendedor forjado por generaciones sucesivas, Costa Rica va a seguir siendo una luz brillante en el mundo, un lugar especial en las Américas donde la violencia circundante no llega y más bien se aplaca, donde se ensayan y se perfeccionan nuevas formas para generar bienestar que luego se difunden en otros pueblos, donde la solidaridad encuentra siempre la forma de preservarse y de renovarse, donde la mano protectora del Creador es siempre fuerte y poderosa. (Figueres O 98)

El epílogo de Rodríguez 02 consta de 8 extensos párrafos. Carece de título; su linde de inicio se marca mediante el vocativo "señoras y señores diputados, costarricenses". La estructura temática es la siguiente:

P108 Todas nuestras acciones, todo lo que hemos hecho y todo lo que nos falta por hacer, tienen un propósito y un sentido.

P109Los guiaba la confianza en sus capacidades y la fe en el futuro que podían construir juntos.

P110 Con fe en nuestro futuro común y confianza en nuestras capacidades, podemos hacer realidad el sueño costarricense de construir el país del desarrollo humano.

P111 Mañana, un niño de cuatro años irá, como cada día, a sus clases de materno infantil, que ahora, por primera vez, se imparten en nuestra educación pública.

P112 Su padre recibirá dos pensiones, y no una, gracias a la Ley de Protección al Trabajador y también tendrá acceso a los importantes ahorros que habrá acumulado en el Fondo de Capitalización Laboral.

P113 Por el bienestar de miles y miles de niñas y niños como ese que mañana irá a sus clases de materno infantil, valen la pena todos nuestros esfuerzos.

P114 Para encontrar el mejor modo de hacer realidad esas oportunidades, bastará buscar en lo mejor de nuestra tradición.

P115 Y ocurriendo, una vez más, a la solución costarricense, seremos capaces una vez más de construir ese futuro de oportunidades que hoy se abre ante nosotros. (Rodríguez 02) 
Pacheco 06 constituye el último MP propiamente dicho, por ser el último de su administración. Se caracteriza por su comparativa brevedad (es el más corto del período, exceptuando Arias 08). Asimismo es breve su epílogo: aunque consta de nueve párrafos, todos ellos se componen de una sola oración, por lo cual su estructura temática coincide con el texto completo. Se titula "Con la conciencia tranquila":

\footnotetext{
P162 Me voy tranquilo con mi conciencia: hice todo lo que pude por este pueblo bueno.

P163 Hice un Gobierno responsable y prudente.

P164 A pesar de las presiones de uno y otro lado, con responsabilidad preservé la estabilidad económica y con prudencia logramos mantener la paz social.

P165 Aún en medio de las más críticas circunstancias, siempre fue patente mi absoluto respeto y decidida colaboración con las autoridades del Poder Judicial para perseguir y sancionar la corrupción.

P166 No hay en mi bolsillo un cinco mal habido; no hay en mis convicciones una sola torcedura; el único premio que me llevo es la serenidad de mi espíritu.

P167 Invertí mi capital político en defender mis principios y ser fiel a mis convicciones.

P168 No hay mejor inversión que esa porque retribuye, con elevados réditos, en beneficio de la herencia moral que dejo a mis hijos y a mis nietos.

P169 Junto a los avances en materia social, económica y ambiental, entrego de herencia a todos los costarricenses la certeza de haber tenido un Presidente honrado y bien intencionado.

P170 Así las cosas: hasta siempre y muchas gracias. (Pacheco 06)
}

El último documento del corpus, Arias 08, se incluyó por ser el último MP que fue emitido al término de la investigación. Por tratarse de una administración en proceso, el mensaje es breve, y su epílogo, además de que cuenta con solo dos párrafos, tiene características diferentes a los epílogos del fin de una administración. Su linde de inicio está marcado por el vocativo "señor Presidente, señoras y señores diputados". Como una característica recurrente del estilo argumentativo de Arias, en este epílogo se utilizan estratégicamente dos citas literarias: de un escritor universal (Esquilo) en el primer párrafo, y de un escritor costarricense (Debravo), en el segundo:

\begin{abstract}
P39 Hace dos mil quinientos años, el gran dramaturgo griego Esquilo escribió: "un solo voto puede derribar o levantar una casa". He venido aquí cargando las preocupaciones de un Presidente, espero salir de aquí cargando la confianza de un ciudadano. Si hemos de construir una casa segura para todos los costarricenses, debemos empezar por esta casa de democracia.

P40 Sea que veamos el vaso medio lleno o medio vacío, tenemos que entender que el vaso se encuentra apenas por la mitad. De nosotros depende que sea una copa rebosante al llegar al final. Hemos cosechado muchos éxitos, hemos conquistado muchas cimas. Los mejores días de Costa Rica están aún por venir, pero tenemos que prepararnos para ellos. Hago mías las palabras del poeta Jorge Debravo cuando dijo: "Os digo que seréis como campanas, como vientos o ritmos... que romperéis fronteras, miedos, cárceles, soledades y círculos, que el infinito no os torturará, porque vosotros sois el infinito". El futuro será mejor porque nosotros somos el futuro. Nuestro destino será tan grande como queramos construirlo. (Arias 08)
\end{abstract}

\title{
3. Conclusión
}

En la Tabla 6 podemos apreciar cómo fue modificándose el peso del epílogo en el total del MP a lo largo de los cuatro períodos: mientras que en los tres primeros solo por excepción se destinó más de 3,6\% del total del MP al epílogo, en el cuarto período se destinó hasta el 12,3\% del total de palabras (Arias 90 y Calderón F 94). Los casos de excepción en los períodos anteriores fueron Aguilar 20 (5,3\%) y Carazo 82 (8,9\%); ambos MPs fueron los últimos de sus respectivos períodos. Tomando en cuenta que cada período terminó con una grave crisis político-económica, este puede ser el factor que explica por qué el epílogo de esos MPs fue más extenso que lo normal. En la Tabla 6 podemos apreciar la relación entre el peso que dio el emisor al exordio y el que destinó al epílogo, así como también el peso que soporta cada uno de estos dos segmentos, que sirven de marco al cuerpo del discurso, en relación con la totalidad 
del MP. A diferencia de las Tablas 2-5, en las que estos datos cuantitativos se presentaron por períodos individuales, en la Tabla 6 el corpus total aparece en orden ascendente por la extensión que cada emisor dedicó al epílogo de su MP.

Por último, la Tabla 6 permite ilustrar un rasgo de estilo en los MPs que podríamos llamar estilo sintáctico a nivel de párrafos: se refiere al promedio de palabras por párrafo en cada uno de los discursos. Al menor número de palabras por párrafo corresponde un estilo más conciso y simple en la estructura sintáctica del párrafo, mientras que al mayor número, un estilo más elaborado y complejo. Estos datos se muestran en la columna Tpal/TP, en la que se consigna el resultado de dividir el número total de palabras en cada MP por el número total de párrafos. Los emisores de párrafos más concisos utilizan de 30 a 50 palabras promedio por párrafo; en este estilo se sitúan Figueres F 58 y 74, Calderón F 94 y Pacheco 06; el promedio general de 96.57 palabras por párrafo se puede ubicar en un rango prototípico de entre 80 y 125 palabras por párrafo. Por último, Jiménez 28 es el MP que se muestra atípico en esta medición, con un promedio de 227 palabras por párrafo, un MP de estilo medular ${ }^{12}$ que consta de solo 25 párrafos y 5.687 palabras.

Tabla 6. Relación cuantitativa entre el exordio, el cuerpo y el epílogo del MP

\begin{tabular}{|c|c|c|c|c|c|c|c|c|c|c|c|}
\hline \multirow{2}{*}{ MP } & \multirow{2}{*}{ Periodo } & \multicolumn{3}{|c|}{ MP: TOTALES } & \multicolumn{3}{|c|}{ EXORDIO } & \multirow{2}{*}{$\begin{array}{c}\text { CUERPO } \\
\text { párrafos }\end{array}$} & \multicolumn{3}{|c|}{ EPÍLOGO } \\
\hline & & párrafos & palabras & $\begin{array}{l}\text { Tpal/ } \\
\text { TP }\end{array}$ & párrafos & palabras & $\begin{array}{c}\% \text { de } \\
\text { palabras }\end{array}$ & & párrafos & palabras & $\begin{array}{c}\% \text { de } \\
\text { palabras }\end{array}$ \\
\hline 04-Jiménez 14 & I & 12 & 1140 & 95 & 1 & 19 & 1.6 & 11 & 0 & 0 & 0.0 \\
\hline 03-González V 10 & I & 290 & 16464 & 57 & 6 & 553 & 3.4 & 283 & 1 & 36 & 0.2 \\
\hline 06-Tinoco 19 & I & 116 & 10226 & 88 & 2 & 170 & 1.6 & 113 & 1 & 72 & 0.7 \\
\hline 20-Trejos 70 & III & 446 & 43709 & 98 & 2 & 327 & 0.7 & 438 & 6 & 485 & 1.1 \\
\hline 08 -Acosta 24 & II & 94 & 9028 & 96 & 5 & 635 & 7.0 & 84 & 5 & 122 & 1.3 \\
\hline 19-Orlich 66 & III & 104 & 10427 & 100 & 5 & 218 & 2.0 & 97 & 2 & 144 & 1.4 \\
\hline 05-González F 16 & I & 203 & 23742 & 117 & 2 & 111 & 0.5 & 198 & 3 & 383 & 1.6 \\
\hline 14-Picado 47 & II & 108 & 13591 & 126 & 1 & 35 & 0.3 & 104 & 3 & 234 & 1.7 \\
\hline 16-Ulate 53 & III & 189 & 15179 & 80 & 17 & 1885 & 12.4 & 169 & 4 & 283 & 1.8 \\
\hline 12-Cortés 40 & II & 134 & 9677 & 72 & 7 & 554 & 5.7 & 125 & 2 & 201 & 2.0 \\
\hline 02-Esquivel 06 & $\mathrm{I}$ & 52 & 6496 & 125 & 15 & 2325 & 35.8 & 35 & 2 & 153 & 2.3 \\
\hline 09-Jiménez 28 & II & 25 & 5687 & 227 & 1 & 228 & 4.0 & 22 & 2 & 137 & 2.4 \\
\hline 17-Figueres F58 & III & 100 & 4451 & 45 & 11 & 475 & 10.6 & 85 & 4 & 121 & 2.7 \\
\hline 10-González V 32 & II & 111 & 11398 & 103 & 3 & 239 & 2.1 & 106 & 2 & 320 & 2.8 \\
\hline 13-Calderón G 44 & II & 58 & 6665 & 115 & 2 & 199 & 3.0 & 54 & 2 & 197 & 3.0 \\
\hline 18-Echandi 62 & III & 91 & 11118 & 122 & 11 & 1458 & 13.1 & 78 & 2 & 323 & 3.0 \\
\hline 22-Oduber 78 & III & 84 & 7135 & 85 & 1 & 59 & 0.8 & 79 & 4 & 238 & 3.1 \\
\hline 11-Jiménez 36 & II & 39 & 4819 & 124 & 0 & 0 & 0 & 37 & 2 & 166 & 3.4 \\
\hline
\end{tabular}




\begin{tabular}{|c|c|c|c|c|c|c|c|c|c|c|c|}
\hline \multirow{2}{*}{ MP } & \multirow{2}{*}{ Periodo } & \multicolumn{3}{|c|}{ MP: TOTALES } & \multicolumn{3}{|c|}{ EXORDIO } & \multirow{2}{*}{\begin{tabular}{|c|} 
CUERPO \\
párrafos
\end{tabular}} & \multicolumn{3}{|c|}{ EPÍLOGO } \\
\hline & & párrafos & palabras & $\begin{array}{c}\text { Tpal/ } \\
\text { TP }\end{array}$ & párrafos & palabras & $\begin{array}{c}\% \text { de } \\
\text { palabras }\end{array}$ & & párrafos & palabras & $\begin{array}{c}\% \text { de } \\
\text { palabras }\end{array}$ \\
\hline 15-Figueres F49 & II & 41 & 4609 & 120 & 1 & 76 & 1.6 & 37 & 3 & 165 & 3.5 \\
\hline 21-Figueres F 74 & III & 23 & 810 & 35 & 6 & 195 & 24.0 & 16 & 1 & 29 & 3.5 \\
\hline 29-Pacheco 06 & IV & 170 & 5408 & 32 & 9 & 268 & 5.0 & 152 & 9 & 186 & 3.5 \\
\hline 01-Iglesias 02 & I & 41 & 3684 & 90 & 2 & 315 & 8.5 & 37 & 2 & 133 & 3.6 \\
\hline 30-Arias 08 & IV & 40 & 3763 & 94 & 6 & 763 & 20.2 & 32 & 2 & 180 & 4.8 \\
\hline 28-Rodríguez 02 & IV & 115 & 11664 & 101 & 11 & 728 & 6.2 & 96 & 8 & 582 & 5.0 \\
\hline 07-Aguilar 20 & I & 33 & 3740 & 113 & 1 & 97 & 2.6 & 30 & 2 & 199 & 5.3 \\
\hline 27-Figueres O 98 & IV & 78 & 8982 & 115 & 2 & 157 & 1.7 & 71 & 5 & 626 & 7.0 \\
\hline 24-Monge 86 & IV & 87 & 7976 & 92 & 2 & 63 & 0.8 & 78 & 7 & 669 & 8.4 \\
\hline 23-Carazo 82 & III & 184 & 17888 & 97 & 8 & 544 & 3.0 & 151 & 25 & 1599 & 8.9 \\
\hline 25-Arias 90 & IV & 71 & 6455 & 91 & 12 & 1216 & 18.8 & 50 & 9 & 794 & 12.3 \\
\hline 26-Calderón F 94 & IV & 233 & 9723 & 42 & 4 & 198 & 2.0 & 200 & 29 & 1197 & 12.3 \\
\hline
\end{tabular}

\section{Notas}

1. El dígrafo MP que se ha adoptado en esta investigación para referirse al último mensaje de la administración es puramente ad hoc, por cuanto los cuatro informes anuales reciben la denominación "mensaje". Por otra parte, para efectos de este artículo, resulta innecesario especificarlo aún más, por ejemplo con la etiqueta "MP4", lo cual obviamente deberá hacerse si se llega a trabajar con los cuatro mensajes (MP1, MP2, MP3 y MP4).

2 Con este término genérico me refiero tanto al Congreso, antes de 1949, como a la Asamblea Constituyente de 1949 y a la actual Asamblea Legislativa.

3. Hernández Mata 1995 analiza un discurso (no un MP) de Rafael Ángel Calderón Guardia.

4. Otras tesis que abordan el discurso presidencial costarricense desde otras disciplinas son Mena y Soto 1997, Zeledón Torres 1991 y Zamora Ovares 2000.

5. Entre estas obras se cuentan: Fernández 1989, Quesada Camacho 1989, Jiménez Ardón 1993, González 1994, Arguedas 2000 y Hernández 2000.

6. Para ese momento no habían sido incorporados al corpus los dos últimos mensajes del corpus actual: Pacheco 2006 y Arias 2008.

7. Más detalles sobre la segmentación de los textos, en Jara Murillo 2006. 
8. Por considerarlo más apropiado a nuestro uso americano, utilizo aquí el término "antepresente" acuñado por Andrés Bello (en Bello y Cuervo 1977: 222- 3) para el tiempo verbal que la Real Academia Española denomina "pretérito perfecto compuesto", esto es, la forma compuesta por el auxiliar haber en presente y el participio del verbo.

9. Véanse en la Tabla del Anexo 1 las distintas denominaciones que tuvo el grupo opositor; en el caso de Echandi fue el Partido Unión Nacional.

10. Una breve caracterización del contexto histórico en que se producen estos MPs puede encontrarse en Jara Murillo en prensa, apartado 3.3.6.2, en donde se propone la segmentación del corpus con base en los hechos sociopolíticos que ocurrieron en el país a lo largo del siglo XX.

11. Grimes (1975) concibe la estructura temática de un texto dentro de un subsistema textual que denomina perspectiva (staging). La perspectiva se refiere al punto de vista desde el cual cada sección del discurso se le presenta al oyente. "Normally [staging relationships] make one part of a stretch of discourse the THEME or TOPIC and relate everything else to it" (1975: 113). La perspectiva funciona en varios niveles: a) la estructura temática que crea el escenario para el discurso total; b) la estructura temática involucrada en las cláusulas; y c) la estructura temática a niveles intermedios: oraciones, párrafos, etc. "Every clause, sentence, paragraph, episode and discourse is organized around a particular element that is taken as point of departure. It is as though the speaker presents what he wants to say from a particular perspective." (1975: 323)

En la descripción de la estructura temática que se presenta en este apartado, la primera oración constituye el tema del párrafo, de modo que la estructura temática del epílogo está constituida por las oraciones iniciales de párrafo. A este respecto véase también Brown y Yule (1993:132).

12. Acerca de la distinción entre los estilos medular y verboso en el MP, véase Jara Murillo (en prensa), sección 3.3.6.4.2.

\section{Bibliografía}

Arguedas, Cecilia. 2000. "Análisis de un discurso político a propósito del Parlamento Centroamericano”. En: Pochet Coronado, R.M. (comp.), 247-277.

Aristóteles. 1953. Retórica. Edición del texto con aparato crítico, traducción, prólogo y notas de Antonio Tovar. Madrid: Instituto de Estudios Políticos.

Bello, Andrés y Rufino J. Cuervo. 1977. Gramática de la lengua castellana. $10^{\mathrm{a}}$ ed. Buenos Aires: Sopena Argentina.

Brown, Gillian y George Yule. 1993. Análisis del discurso. Madrid: Visor.

Brown, Penelope y Stephen C. Levinson. 1987. Politeness. Some universals in language usage. Cambridge: Cambridge University Press.

Carbaugh, Donal. 2007. "Ethnography of Communication.” En: Donsbach, Wolfgang (ed.). The Blackwell International Encyclopedia of Communication. Blackwell Publishing. Blackwell Reference Online. 30 de octubre de 2007. http://www.blackwellreference. com/subscriber/tocnode?id=g9781405131995_chunk_g9781405131995397. 
Fernández, Óscar. 1989. "De una teoría de la conciencia al análisis de la producción discursiva”. En: Fernández, Óscar (comp.), 229-258.

Fernández, Óscar (comp). 1989. Sociología: Teoría y métodos. San José: Educa.

Fonseca, Elizabeth (comp.). 1989. Historia: Teoría y métodos. San José: Educa, 267-303.

González, Alfonso. 1994. El discurso de la Patria. Estructuras simbólicas del poder. San José: Editorial de la Universidad de Costa Rica.

Grimes, Joseph. 1975. The thread of discourse. Berlin/New York/Amsterdam: Mouton.

Halliday, M.A.K. y Ruqaiya Hasan. 1989. Language, context, and text: aspects of language in a social semiotic perspective. Oxford: Oxford University Press.

Hernández, Gerardo. 2000. "El discurso del Pacto Figueres-Calderón. Un ejercicio de análisis estructural del discurso”. En: Pochet Coronado, R.M. (comp.), 209-246.

Hernández Mata, Francisco José. 1995. “La manipulación textual en el discurso de reapertura de la "Universidad Nacional” por el Dr. Rafael Ángel Calderón Guardia, presidente de la República de Costa Rica, año de 1941”. Káñina. Revista de Artes y Letras de la Universidad de Costa Rica. 19 (2): 15-30.

Hymes, Dell. 1974. Foundations in sociolinguistics: An ethnographic approach. Philadelphia: University of Pennsylvania Press.

1986. "Models of interaction in language and social life". En: Hymes, D. y J. Gumperz (eds.), 35-71.

Hymes, D. y J. Gumperz (eds.). 1986. Directions in Sociolinguistics. The ethnography of communication. Oxford/New York: Blackwell (previously copyright: Holt, Rinehart y Winston, 1972).

Jakobson, Roman. 1988. Lingüística y Poética. Madrid: Cátedra.

Jara Murillo, Carla Victoria. 2006. "Discurso presidencial costarricense: estructura formal y tópica del último mensaje ante los diputados (1902-2002)". Revista de Filología y Lingüística de la Universidad de Costa Rica. 32 (2): 141-183.

2008. “Tópicos y funciones comunicativas en los exordios de los Mensajes Presidenciales del $1^{\circ}$ de mayo (1902-2002)". Revista Parlamentaria. 16 (2): 65-117.

En prensa (2007). "El mensaje presidencial costarricense desde la etnografía de la comunicación". Revista de Filología y Lingüística de la Universidad de Costa Rica. 33 (2): 141-178. 
Jiménez Ardón, Óscar. 1993. Cómo hacer análisis ideológico: propuesta de método para analizar ideológicamente un discurso a partir de los discursos del presidente Lic. Rafael Ángel Calderón Fournier a la Asamblea Legislativa, mayo 1990-1992. San José: Centro de Estudios y Publicaciones ALFORJA.

Mena, Rosibel y Annette Soto. 1997. Análisis del juego táctico utilizado por José María Figueres Olsen en sus discursos presidenciales de mayo 1994, 1995, 1996 y 1997. Tesis de licenciatura en Periodismo: Universidad de Costa Rica.

Pendones de Pedro, Covadonga. 1991. Análisis del discurso político en Centroamérica. Tesis de doctorado en Lingüística: Universidad Autónoma de Madrid.

Pochet Coronado, Rosa María (comp.). 2000. Discurso y análisis social. San José: Editorial de la Universidad de Costa Rica.

Quesada Camacho, Juan Rafael. 1989. "Historiografía: Elementos para su estudio". En: Fonseca, Elizabeth (comp.), 267-303.

Quesada Pacheco, Jorge Arturo. 1989. "Aportes de la lingüística al estudio del discurso persuasivo". Revista de Filología y Lingüística. 15 (1): 145-147.

1994. "Política y sociolingüística". Revista de Ciencias Jurídicas. 78: 85-96.

1997. Los discursos de los políticos de Costa Rica. San José: EUNED.

2001. Estrategias de los políticos para solicitar nuestros votos. Heredia: EUNA.

Saville-Troike, Muriel. 1989. The ethnography of communication: an introduction. $2^{\mathrm{a}}$ ed. Oxford: Blackwell.

van Dijk, Teun. 1999. “¿Qué es el análisis del discurso político?”. En: van Dijk, T. e Iván Rodrigo, 9-103.

van Dijk, T. e Iván Rodrigo. 1999. Análisis del Discurso Social y Político. Quito: Abya Yala.

Zamora Ovares, Óscar. 2000. El discurso político como instrumento de dominación: los discursos presidenciales de José María Figueres Olsen de 1995 a 1998. Tesis de licenciatura en Sociología: Universidad de Costa Rica.

Zeledón Torres, Fernando. 1991. La Paz y el Discurso Político Nacional: los casos de los discursos del Dr. Oscar Arias Sánchez y del periódico La Nación 1985-1987. Tesis de maestría en Sociología: Universidad de Costa Rica. 


\section{Anexo 1}

\section{Presidente Emisor, Partido, Administración y Fecha de los MPs}

\begin{tabular}{|c|c|c|c|c|}
\hline Identificación & Presidente & Partido político & Administración & Fecha del MP \\
\hline Iglesias 02 & Rafael Iglesias Castro & Partido Civil & $1898-1902$ & $1^{\circ}$ de mayo de 1902 \\
\hline Esquivel 06 & Ascensión Esquivel Ibarra & Partido Unión Nacional & 1902-1906 & $1^{\circ}$ de mayo de 1906 \\
\hline González V 10 & Cleto González Víquez & Partido Unión Nacional & $1906-1910$ & $1^{\circ}$ de mayo de 1910 \\
\hline Jiménez 14 & Ricardo Jiménez Oreamuno & Partido Republicano & $1910-1914$ & $1^{\circ}$ de mayo de 1914 \\
\hline González F 16 & Alfredo González Flores & Partido Republicano & $1914-1917$ & $1^{\circ}$ de mayo de 1916 \\
\hline Tinoco 19 & Federico Tinoco Granados & (golpe de estado) & $1917-1919$ & $1^{\circ}$ de mayo de 1919 \\
\hline Aguilar 20 & Francisco Aguilar Barquero & Partido Republicano & $1919-1920$ & $1^{\circ}$ de mayo de 1920 \\
\hline Acosta 24 & Julio Acosta García & Partido Republicano & $1920-1924$ & $1^{\circ}$ de mayo de 1924 \\
\hline Jiménez 28 & Ricardo Jiménez Oreamuno & Partido Republicano & $1924-1928$ & $1^{\circ}$ de mayo de 1928 \\
\hline González V 32 & Cleto González Víquez & Partido Unión Nacional & $1928-1932$ & $1^{\circ}$ de mayo de 1932 \\
\hline Jiménez 36 & Ricardo Jiménez Oreamuno & P. Republicano Nacional & $1932-1936$ & $1^{\circ}$ de mayo de 1936 \\
\hline Cortés 40 & León Cortés Castro & P. Republicano Nacional & $1936-1940$ & $1^{\circ}$ de mayo de 1940 \\
\hline Calderón G 44 & Rafael Ángel Calderón Guardia & P. Republicano Nacional & $1940-1944$ & $1^{\circ}$ de mayo de 1944 \\
\hline Picado 47 & Teodoro Picado Michalski & P. Republicano Nacional & 1944-1948 & $1^{\circ}$ de mayo de 1947 \\
\hline Figueres F 49 & José Figueres Ferrer & (proceso revolucionario) & $1948-1949$ & 16 de enero de 1949 \\
\hline Ulate 53 & Otilio Ulate Blanco & Partido Unión Nacional & $1949-1953$ & $1^{\circ}$ de mayo de 1953 \\
\hline Figueres F 58 & José Figueres Ferrer & P. Liberación Nacional & $1953-1958$ & $1^{\circ}$ de mayo de 1958 \\
\hline Echandi 62 & Mario Echandi Jiménez & Partido Unión Nacional & $1958-1962$ & $1^{\circ}$ de mayo de 1962 \\
\hline Orlich 66 & Francisco Orlich Bolmarcich & P. Liberación Nacional & $1962-1966$ & $1^{\circ}$ de mayo de 1966 \\
\hline Trejos 70 & José Joaquín Trejos Fernández & P. Unificación Nacional & $1966-1970$ & $1^{\circ}$ de mayo de 1970 \\
\hline Figueres F 74 & José Figueres Ferrer & P. Liberación Nacional & $1970-1974$ & $1^{\circ}$ de mayo de 1974 \\
\hline Oduber 78 & Daniel Oduber Quirós & P. Liberación Nacional & 1974-1978 & $1^{\circ}$ de mayo de 1978 \\
\hline Carazo 82 & Rodrigo Carazo Odio & Coalición Unidad & $1978-1982$ & $1^{\circ}$ de mayo de 1982 \\
\hline Monge 86 & Luis Alberto Monge Álvarez & P. Liberación Nacional & $1982-1986$ & $1^{\circ}$ de mayo de 1986 \\
\hline Arias 90 & Óscar Arias Sánchez & P. Liberación Nacional & $1986-1990$ & $1^{\circ}$ de mayo de 1990 \\
\hline Calderón F 94 & Rafael Ángel Calderón Fournier & P. Unidad Socialcristiana & 1990-1994 & $1^{\circ}$ de mayo de 1994 \\
\hline
\end{tabular}




\begin{tabular}{|c|c|c|c|c|}
\hline Identificación & Presidente & Partido político & Administración & Fecha del MP \\
\hline Figueres O 98 & José María Figueres Olsen & P. Liberación Nacional & 1994-1998 & $1^{\circ}$ de mayo de 1998 \\
\hline Rodríguez 02 & Miguel A. Rodríguez Echeverría & P. Unidad Socialcristiana & $1998-2002$ & $1^{\circ}$ de mayo de 2002 \\
\hline Pacheco 06 & Abel Pacheco de la Espriella & P. Unidad Socialcristiana & $2002-2006$ & $1^{\circ}$ de mayo de 2006 \\
\hline Arias 08 & Óscar Arias Sánchez & P. Liberación Nacional & 2006-2010 & $1^{\circ}$ de mayo de 2008 \\
\hline
\end{tabular}

\title{
Anexo 2
}

\section{Epílogos completos del IV Período}

\author{
Monge 86 \\ S32 Diálogo y consenso nacional \\ S32.1 [Vocat:] Señores diputados: \\ P80 Saber escuchar es, a mi juicio, una de las principales obligaciones de un Jefe de Estado. ¡Ay de aquel \\ Presidente de la República que no sepa escuchar a su pueblo! En una democracia pluralista, como es \\ Costa Rica, la fuerza de un conductor está en interpretar adecuadamente a quienes lo han elegido y aun \\ a aquellos que no le otorgaron su confianza en las urnas electorales. \\ P81 No se llega a la Presidencia de la República a imponer verticalmente las propias ideas. Se llega a \\ asumir la inmensa responsabilidad de dirigir, legítimamente, los destinos de la Nación. En Costa Rica, la \\ prudencia y la moderación son virtudes que el gobernante debe practicar cotidianamente y por ello, antes \\ de utilizar los mecanismos institucionales de poder público, es necesario escuchar atentamente la voz del \\ pueblo. No se trata de ser débil, ni de transigir con la intolerancia o la arrogancia. La fuerza de las ideas \\ es siempre superior a cualquier otra fuerza humana. Se trata de interpretar y orientar adecuadamente las \\ aspiraciones nacionales. Se trata de ejercer el mando con firmeza, pero a la vez con el menor margen de \\ error. Se trata de evitarle, por equivocación o premura, daños mayores a la República. \\ P82 Por ello, desde el 8 de mayo de 1982, impuse la norma del diálogo y el consenso como fundamento \\ de la acción de mi Gobierno. Creo que he cumplido y siempre he estado abierto a escuchar. También mi \\ más directos colaboradores en el Poder Ejecutivo. \\ P83 He escuchado a los sectores organizados y también, por encima de unos y otros, poderosos o no \\ poderosos, he estado permanentemente atento a la voz del pueblo y así, durante estos cuatro años, he \\ sido un viajero infatigable de la geografía nacional. A los pueblos he ido a conversar y a oír. Siempre he \\ puesto, igualmente, atención a la opinión crítica de la prensa. Diálogo y consenso nacional fueron por \\ ello normas de conducta obligada en esta Administración y creo, estoy firmemente convencido, que sólo \\ así se puede gobernar en un país de la cultura cívica y política de Costa Rica. \\ S32.2 [Vocat:] Señores diputados: \\ P84 Ustedes encontrarán los detalles de esta rendición de cuentas en los informes parciales que, conforme \\ a la Constitución Política, los Señores Ministros y Presidentes Ejecutivos entregarán a la Asamblea \\ Legislativa. En este mensaje me he limitado, al igual que en los años anteriores, a expresarles mis puntos \\ de vista sobre los aspectos que, a mi juicio, son los más importantes de mi gestión como Presidente \\ de la República. Los remito a ustedes a los informes parciales de los Señores Ministros y Presidentes \\ Ejecutivos de las instituciones autónomas del Estado. \\ S32.3 [Vocat:] Señores diputados: \\ P85 Este es mi último mensaje a la Asamblea Legislativa. Dentro de siete días, el 8 de mayo, a las doce \\ del día, entregaré la Presidencia de la República a mi legítimo sucesor. El pueblo se expresó en las urnas \\ electorales. El pueblo, en absoluta libertad, escogió el futuro Presidente de la República. En las personas
}


de ustedes, como representantes del pueblo, quiero agradecerle a los costarricenses el inmenso honor que hicieron al depositar en mí su confianza para dirigir los destinos de Costa Rica del 8 de mayo de 1982 al 8 de mayo de 1986. Nunca podré pagar tanta bondad. Nunca podré pagar el cariño de mi pueblo. Siempre vivirá en mí, con humildad, el amor inmenso que, en estos cuatro años, le profesé a Costa Rica. Ante Dios, ante mi pueblo, ante mi conciencia, creo que he cumplido mis responsabilidades con Costa Rica. S32.4 [Vocat:] Señores diputados:

P86 Juntos hemos salvado la Paz... Juntos hemos apuntalado nuestro sistema de vida en Libertad... -y solo juntos- podremos ganar las batallas que resta dar por la producción y contra la pobreza...

P87 Juntos -y solo juntos- podremos cumplir el compromiso histórico, de heredar a las futuras generaciones una Costa Rica en paz y libertad -sí, en paz y libertad- pero también heredar una Costa Rica más justa, más equitativa, más solidaria y con menos pobreza... Muchas Gracias.

\section{Arias 90}

S8 Amigas y amigos míos:

P63 En pocos días entregaré el Gobierno. Lo haré en paz con mi pueblo, porque trabajé sin descanso por cada una de las cosas por las que les pedí el voto. He dejado para el final el referirme a la lucha contra la corrupción y el narcotráfico, a la ley de la promoción de la igualdad social de la mujer y el hombre, y al robustecimiento de nuestro sistema legal con la creación de la Sala IV de la Corte Suprema de Justicia.

P64 Siempre sostuve que Costa Rica podría vencer cualquier obstáculo cuando las causas que emprendía eran aquellas en las que lograba un amplio consenso, por encima de divisiones políticas. Solíamos poner, como grandes ejemplos de estos logros, lo que habíamos hecho con la educación y la salud. Ahora agrego con alegría, como ejemplos, la paz y la vivienda. Allí donde todo parecía imposible, juntos logramos la paz y juntos levantamos las viviendas prometidas. Esto también habrá de ser verdad con la Ley de promoción de la igualdad social de la mujer y el hombre. Juntos aprobamos la ley y ahora deberemos también juntos cambiar las actitudes y los comportamientos para asegurarnos la participación plena de la mujer en nuestra sociedad. Esa incorporación será la mejor garantía de que somos capaces de transformarnos en un país desarrollado.

P65 Para el robustecimiento de nuestra democracia, para asegurarnos el respeto mutuo entre gobernantes y gobernados, nada es más sagrado que velar por la honestidad de los servidores públicos. Separé de su cargo a todo aquel sobre el cual cayeron sospechas fundadas. Más importante fue el que el país entero se puso de acuerdo en una decisiva cruzada por la moralidad. Así fue como establecimos la Comisión de Rescate Valores y realizamos numerosas acciones destinadas a garantizar la limpieza de la función pública.

P66 También por consenso aprobamos la Ley de Psicotrópicos, que es una de las más avanzadas del mundo para combatir el narcotráfico. Como tantas veces lo he repetido, estoy seguro de que unidos seremos capaces de desterrar para siempre esta amenaza de nuestra tierra. Fueron expulsados del país 2.388 extranjeros indeseables y la tecnificación de nuestros cuerpos policiales ha paralizado ya muchas acciones criminales.

P67 Nos complace haber convertido en realidad, la Sala IV de la Corte Suprema de Justicia con jurisdicción constitucional. Se trata de una de las instituciones judiciales más importantes creadas en la segunda mitad de este siglo y su funcionamiento reforzará la fe en el régimen de Derecho. En muchas otras materias también se dio este consenso que transformó a Costa Rica en ganadora.

P68 Quiero señalar también que como la Constitución requiere mayoría calificada para empréstitos externos, hubo ocasiones en que estas mayorías se postergaron largamente en el tiempo por razones políticas o simplemente no se lograron por las mismas razones. Este modo de hacer oposición daña considerablemente las posibilidades de un mayor desarrollo nacional. Desde donde esté, haré todo lo posible porque estas actitudes pequeñas y mezquinas no se repitan, simplemente porque Costa Rica no se las merece.

P69 Quiero dar las gracias a quienes me acompañaron en mi gestión de gobierno, desde el ministro de cada cartera hasta el más humilde servidor público. Conté siempre con la lealtad de todos ellos. Mis ministros dejarán sus cargos no tan sólo con la satisfacción de salir sin una sola mancha de corrupción, sino que también con el orgullo de haber dirigido en cada caso una tarea importante y noble para el engrandecimiento de Costa Rica.

P70 Las últimas páginas de este siglo nos presentarán retos como pocas veces en la historia. No hemos salido de la Guerra Fría para caer en un progresivo calentamiento de la Tierra por el descuido del medio ambiente. No hemos salido del estatismo que estrangulaba a nuestras economías para caer en un egoísmo que generalice la pobreza. No hemos derrotado la guerra para contentarnos con la miseria y la división. Es hora para el desarrollo, pues sólo así se robustecerán las democracias. Es hora de definir ese desarrollo sostenible donde la naturaleza será respetada. Es hora de trabajar en una agenda de cooperación y no de 
confrontación. Más que demonios por derrotar, nos queda como reto construir los caminos nuevos del desarrollo compartido, la paz estable y la democracia indestructible.

P71 Recibí el Gobierno hace cuatro años de don Luis Alberto Monge. El país había progresado con él sustancialmente. Me entregó un país mucho mejor que el que había recibido. Yo haré lo mismo. Al entregar el gobierno, será Costa Rica más grande y estará robustecida en su paz y en su desarrollo. Confío en que mi sucesor hará la mismo un día. Quiera Dios que todos pongamos cuidado y empeño para no romper nunca esta cadena de la que depende el destino superior de Costa Rica.

\section{Calderón F 94}

S6 V. Reflexiones finales

S6.1

P205 He mencionado algunas de nuestras victorias durante estos 4 años. El tiempo no nos permite incluir a todas. El que siembra, cosecha. Costa Rica ha sembrado, Costa Rica está cosechando. Gracias a la contribución de todos los costarricenses, hoy disfrutamos de los primeros frutos, de los primeros avances, de los primeros logros de una era de prosperidad. Gracias al concurso de los poderes de la República, y especialmente gracias a la contribución de la Honorable Asamblea Legislativa, convertimos obstáculos en soluciones, diques en cauces y reveses en victorias. Pero el camino apenas empieza. Y los mejores frutos y conquistas aún nos esperan en el futuro.

P206 Costa Rica está en el camino correcto. De acuerdo a las características y a las realidades del mundo de la Post- Guerra Fría, estamos en el camino correcto para avanzar hacia el desarrollo con equidad. No debemos retroceder. No podemos y no debemos regresar al pasado.

P207 Hoy entregamos un país con una economía estable y en pleno proceso de expansión. Un país con las tasas de crecimiento más elevadas del mundo.

P208 Hoy entregamos una economía que crea empleos, mejores salarios y una más alta calidad de vida. P209 Hoy entregamos una economía en pleno proceso de modernización y de inserción en la economía mundial.

P210 Hoy entregamos un país con menos inflación, con una de las inflaciones más bajas de la América Latina.

P211 Hoy entregamos un país con menos pobreza, un país con los índices más bajos de pobreza de nuestra historia.

P212 Hoy entregamos un país con 96,000.00 nuevas viviendas.

P213 Pero, sobretodo, hoy entregamos un país con más confianza en sí mismo y con más optimismo en el futuro.

P214 Si continuamos en el camino correcto de la modernización económica, de la austeridad fiscal, de la ética en la función pública, del control de la inflación y de la participación de Costa Rica en la economía mundial, tendremos garantizado un futuro de estabilidad, de crecimiento sostenido y de avance hacia el desarrollo. Por el contrario, si abandonamos el camino correcto, si damos marcha atrás, si volvemos al gigantismo estatal, al proteccionismo, a los privilegios y al aumento en el déficit fiscal, se perderá la confianza, se ahuyentará la inversión y en un corto plazo volveremos a la crisis económica y al pesimismo.

P215 La reforma económica debe continuar. La reforma del Estado debe continuar. La integración al mundo debe profundizarse. La modernización de Costa Rica debe consolidarse. Los índices de equidad social deben ser mejorados. La protección del ambiente debe avanzar. Por el bien de todos, no debemos retroceder. Por el bien de todos, debemos consolidar la era de prosperida [sic].

S6.2 [Vocat:] Honorables Diputados:

P216 Hace cuatro años nos comprometimos ante los padres de nuestra nacionalidad a dirigir un gobierno de consenso nacional, fiel a los principios de nuestra idiosincrasia. Y hace cuatro años nos comprometimos ante los padres de nuestra nacionalidad a convertir los muros de la intolerancia en puertas para la concordia y en puertas para una nueva era de prosperidad. Hoy, estamos aquí para decir con plena satisfacción que hemos cumplido ante los padres de nuestra nacionalidad y que hemos cumplido ante los costarricenses.

P217 Algunos pocos se fijan en nuestros errores. Quisimos dar aún más. Pero nuestros errores y nuestras carencias, gracias a Dios, no pesaron más que nuestras realizaciones. Por eso, hoy vengo con la frente en alto, con la satisfacción del deber cumplido, con la tranquilidad de conciencia de haberme entregado en cuerpo y alma durante cuatro años a este maravilloso pueblo de Costa Rica.

P218 Hace unas semanas dos mujeres costarricenses me escribieron una carta de balance sobre nuestro gobierno. Estas dos costarricenses me decían: “ Reflexionando sobre su labor, en el calor de nuestra casa, hemos decidido que queríamos dejar manifiesto nuestro apoyo a una gestión que nos ha infundido confianza y aliento y nos ha hecho sentir orgullosas del apoyo que un día le dimos y del cariño que le 
profesamos. Hoy, ... repasando su labor, acuden a nosotras unas palabras del poeta José Basileo Acuña, que definen lo que sus cuatro años de gestión nos inspiran:

P219 "Yo miro hacia el pasado y no me asusta, yo miro hacia el futuro y no lo temo, yo miro hacia la altura y la vislumbro, yo miro a la bajura y la comprendo, yo miro en el presente la confluencia de todos los caminos de lo eterno".

P220 Gracias a estas costarricenses por sus palabras y por su aliento.

P221 Salgo, con unos años más, pero salgo enriquecido por la experiencia de dirigir esta República, escuchando las voces y los consejos, no solo de funcionarios y de colaboradores, sino las voces, los consejos del pueblo. Salgo fortalecido en mi lealtad a los valores que han hecho grande a Costa Rica. P222 Ser Presidente de Costa Rica es ser leal a sus valores.

P223 Ser Presidente de Costa Rica es ser un oyente de las aspiraciones y de las necesidades del pueblo. Se ha dicho que en la democracia un hombre que no escucha no puede gobernar. Desde la Presidencia de esta digna República, yo he escuchado con humildad, he reconocido la sabiduría de otros.

P224 Al final de la jornada, en mi corazón solo siento gratitud y agradecimiento hacia ese pueblo y hacia todos los colaboradores que me ayudaron a escuchar la voz de ese pueblo.

P225 Al final de la jornada, en mi corazón solo siento gratitud y agradecimiento, incluso a quienes me vieron como adversario y a quienes yo solo vi como hermanos costarricenses con opinión diferente.

P226 Hay muchos a quienes quiero agradecer. Muchos que contribuyeron en estos años a construir una Costa Rica mejor. Permítanme solamente hacer mención en una persona a las muchas que contribuyeron con su trabajo y con su visión para que esta Administración dejara como herencia un país mejor.

P227 Ella es una persona a quien conozco desde hace 40 años y quien me ha impresionado con su talento y con su valor. Gloria Bejarano ha sido indispensable para mí y para el Presidente de este país.

P228 De ella me ha impresionado su compasión. Ella siente el dolor de cada costarricense que se encuentra. Ella entiende el sueño de cada costarricense con quien habla. Ella quiere convertir en realidad el sueño de cada costarricense.

P229 En Gloria me ha impresionado su visión de optimismo y de futuro. Ella ve alegría donde hay tristeza, ella ve soluciones donde hay problemas, ella ve luz donde hay oscuridad. Ella con gran espíritu durante estos cuatro años convirtió en luz los momentos de oscuridad. Ella no estuvo sola, porque como ella, muchos de mis colaboradores, muchos de los costarricenses, durante estos cuatro años estuvieron con nosotros convirtiendo la oscuridad en luz. A todos ellos los recordaremos por siempre, Gloria y yo, en nuestras oraciones.

P230 Con la ayuda y con la inspiración de Dios, hemos logrado mucho estos últimos años. Dejo la Presidencia de Costa Rica fuerte, vibrante, dinámica y saludable.

P231 Yo estoy orgulloso de esta nación, orgulloso de ser costarricense, orgulloso de decirle a mi sucesor: esta es mi querida Costa Rica. Fortalezcámosla, apoyémosla, animémosla y hagámosla crecer.

P232 Tomemos con cuidado a esta nuestra Costa Rica. Nunca, nunca, permitamos que los costarricenses perdamos el optimismo y la fe en Costa Rica.

P233 ¡Que Dios bendiga a esta República! Muchas gracias.

\section{Figueres 098}

S3.3 3. Mi profundo agradecimiento al pueblo costarricense [Vocat:] Queridas y queridos costarricenses. P74 Mi exposición llega a su fin y no quiero terminarla sin expresar a cada uno de ustedes la inmensa satisfacción y el profundo orgullo que siento por haber podido servirles como su Presidente. Agradezco de corazón las infinitas muestras de cariño, de solidaridad y de apoyo que recibí a lo largo de mi gestión. De ellas me nutrí día tras día para renovar mis energías y redoblar mis esfuerzos en la sagrada tarea de la función pública, la tarea de servir siempre y sin desmayar, en los peligros, en las crisis y en los buenos tiempos.

P75 Durante estos años tan intensos, visité cada rincón del país y estuve en muchas empresas, en muchas comunidades y en muchas instituciones públicas. Recibí delegaciones de muchas organizaciones públicas y privadas. Me enteré de miles de proyectos de nuestros pequeños y grandes empresarios. Palpé la terrible tragedia de familias enlutadas y en ruina por los estragos del Huracán César. Vi también las caras sonrientes y llenas de esperanza de mujeres y hombres que recibían su casa propia, su acueducto rural, o su nueva clínica.

P76 En todo lo que vi y lo que sentí, encontré siempre reflejado el espíritu sabio y generoso de nuestro pueblo. De un pueblo en el que abundan todos los días los actos valerosos de madres jefas de familia para sacar adelante sus hijos, de agricultores que han dejado de talar los bosques para preservarlos y darles usos más sostenibles, de empresarios innovadores que invierten sus capitales en industrias de alta productividad, de jóvenes de la ciudad y del campo que estudian y trabajan a la vez con grandes sacrificios, de funcionarios que libran luchas impresionantes para mantener a flote un servicio público 
o para mejorar una institución. En la inteligencia y en el empeño de estos ciudadanos está la verdadera fuerza que mueve a nuestro pueblo.

P77 En los actos y decisiones innumerables de todos los costarricenses, es donde se ha resuelto la disyuntiva entre ser un país más solidario o ser un país más lleno de egoísmos, entre ser un país más próspero e innovador o ser un país más retrasado y estancado, entre ser un país que se reconcilia con la naturaleza o uno que la trata con violencia y con descuido. Sí hoy podemos decir que Costa Rica es más gobernable y más sostenible que hace cuatro años, si hoy podemos decir que su horizonte es más claro y amplio, es porque su pueblo así lo ha deseado. Por eso, queridos y queridas costarricenses, sean mis últimas palabras para expresar mi inmensa admiración por este pueblo nuestro al que yo he visto construir su destino desde la perspectiva privilegiada de la Presidencia de la República, ese pueblo que no deja de aprovechar lo bueno que conquistó en el pasado para cuidarlo y protegerlo, que no deja de aprender de los errores para buscar nuevas formas de hacer las cosas, que no deja de construir nuevos sueños y nuevos proyectos para seguir progresando en paz como una gran familia.

P78 Con ese espíritu generoso y emprendedor forjado por generaciones sucesivas, Costa Rica va a seguir siendo una luz brillante en el mundo, un lugar especial en las Américas donde la violencia circundante no llega y más bien se aplaca, donde se ensayan y se perfeccionan nuevas formas para generar bienestar que luego se difunden en otros pueblos, donde la solidaridad encuentra siempre la forma de preservarse y de renovarse, donde la mano protectora del Creador es siempre fuerte y poderosa. Con la inexpresable alegría de haber servido a nuestro pueblo desde la posición más alta de la función pública, doy a todos ustedes mi más profundo agradecimiento. Que Dios guarde siempre a Costa Rica. Muchas gracias.

\section{Rodríguez 02}

S3.4 Señoras y señores diputados, costarricenses:

P108 Todas nuestras acciones, todo lo que hemos hecho y todo lo que nos falta por hacer, tienen un propósito y un sentido. Un propósito y un sentido que son de hoy y son de siempre, pues fueron definidos hace casi 181 años por nuestros antepasados, cuando mediante el Pacto de Concordia se abocaron a construir un país único y especial en el concierto de las naciones.

P109 Los guiaba la confianza en sus capacidades y la fe en el futuro que podían construir juntos. Hoy, nosotros, herederos de esa tradición, guiados por una visión compartida de futuro, estamos llamados a continuar el avance por la senda de progreso y desarrollo humano que ellos delinearon.

P110 Con fe en nuestro futuro común y confianza en nuestras capacidades, podemos hacer realidad el sueño costarricense de construir el país del desarrollo humano. Más allá de cualquier diferencia, en este país todos compartimos un compromiso con esa causa, con la causa costarricense de construir un futuro mejor para todos.

P111 Mañana, un niño de cuatro años irá, como cada día, a sus clases de materno infantil, que ahora, por primera vez, se imparten en nuestra educación pública. A sus doce años, es decir dentro de ocho, ese niño podrá ingresar a secundaria como todos los jóvenes de su edad, si continuamos nuestro esfuerzo por universalizar la secundaria. Y como la inflación podrá ubicarse en los niveles internacionales, si hacemos la reforma fiscal, el joven no le creerá a sus padres cuando le hablen sobre los altos niveles de inflación vividos durante las últimas tres décadas. Dentro de 18 años, a sus veintidós, ese joven adulto podrá encontrar un buen empleo en actividades de servicios, manufactura o agricultura ricos en componentes de conocimiento y destinados a los más exigentes mercados del mundo.

P112 Su padre recibirá dos pensiones, y no una, gracias a la Ley de Protección al Trabajador y también tendrá acceso a los importantes ahorros que habrá acumulado en el Fondo de Capitalización Laboral. Sus abuelos, como todos los ancianos de este país, tendrán asegurada una pensión. Sus hijos, como todos los niños del futuro costarricense, tendrán el apellido y la responsabilidad de sus padres gracias a la Ley de Paternidad Responsable. Y si su familia vive en una zona urbana, el diseño de ésta les asegurará mejor calidad de vida.

P113 Por el bienestar de miles y miles de niñas y niños como ese que mañana irá a sus clases de materno infantil, valen la pena todos nuestros esfuerzos. Si aceptamos los retos del presente, la vida de ese niño y su familia estará plena de oportunidades. No les neguemos ese futuro a nuestras niñas y niños.

P114 Para encontrar el mejor modo de hacer realidad esas oportunidades, bastará buscar en lo mejor de nuestra tradición. En los grandes momentos, en las grandes decisiones de nuestra historia, desde los albores de nuestra Nación, siempre hemos tenido la fortuna de contar con la solución costarricense, como señalé en este mismo recinto hace exactamente once años. Contamos con la solución costarricense, una solución basada en el diálogo serio y profundo, en la concertación de voluntades, en la búsqueda constructiva y fructífera de acuerdos que beneficien a todos los sectores e impulsen el desarrollo nacional.

P115 Y ocurriendo, una vez más, a la solución costarricense, seremos capaces una vez más de construir ese futuro de oportunidades que hoy se abre ante nosotros. Démonos, todos, la oportunidad de volverlo realidad y que Dios nos bendiga en ese empeño. Muchas gracias. 


\section{Pacheco 06}

S11 CON LA CONCIENCIA TRANQUILA: [Vocat:] Señoras y señores:

P162 Me voy tranquilo con mi conciencia: hice todo lo que pude por este pueblo bueno.

P163 Hice un Gobierno responsable y prudente.

P164 A pesar de las presiones de uno y otro lado, con responsabilidad preservé la estabilidad económica y con prudencia logramos mantener la paz social.

P165 Aún en medio de las más críticas circunstancias, siempre fue patente mi absoluto respeto y decidida colaboración con las autoridades del Poder Judicial para perseguir y sancionar la corrupción.

P166 No hay en mi bolsillo un cinco mal habido; no hay en mis convicciones una sola torcedura; el único premio que me llevo es la serenidad de mi espíritu.

P167 Invertí mi capital político en defender mis principios y ser fiel a mis convicciones.

P168 No hay mejor inversión que esa porque retribuye, con elevados réditos, en beneficio de la herencia moral que dejo a mis hijos y a mis nietos.

P169 Junto a los avances en materia social, económica y ambiental, entrego de herencia a todos los costarricenses la certeza de haber tenido un Presidente honrado y bien intencionado.

P170 Así las cosas: hasta siempre y muchas gracias.

\section{Arias 08}

S3 Señor Presidente, señoras y señores diputados:

P39 Hace dos mil quinientos años, el gran dramaturgo griego Esquilo escribió: "un solo voto puede derribar o levantar una casa". He venido aquí cargando las preocupaciones de un Presidente, espero salir de aquí cargando la confianza de un ciudadano. Si hemos de construir una casa segura para todos los costarricenses, debemos empezar por esta casa de democracia.

P40 Sea que veamos el vaso medio lleno o medio vacío, tenemos que entender que el vaso se encuentra apenas por la mitad. De nosotros depende que sea una copa rebosante al llegar al final. Hemos cosechado muchos éxitos, hemos conquistado muchas cimas. Los mejores días de Costa Rica están aún por venir, pero tenemos que prepararnos para ellos. Hago mías las palabras del poeta Jorge Debravo cuando dijo: "Os digo que seréis como campanas, como vientos o ritmos... que romperéis fronteras, miedos, cárceles, soledades y círculos, que el infinito no os torturará, porque vosotros sois el infinito". El futuro será mejor porque nosotros somos el futuro. Nuestro destino será tan grande como queramos construirlo. 